\title{
A Death Receptor 6-Amyloid Precursor Protein Pathway Regulates Synapse Density in the Mature CNS But Does Not Contribute to Alzheimer's Disease-Related Pathophysiology in Murine Models
}

\author{
Dara Y. Kallop, ${ }^{1 *}$ William J. Meilandt, ${ }^{2 *}$ Alvin Gogineni, ${ }^{1}$ Courtney Easley-Neal, ${ }^{1}$ Tiffany Wu, ${ }^{2}$ Adrian M. Jubb, ${ }^{3}$ \\ Murat Yaylaoglu, ${ }^{3}$ Mehrdad Shamloo, ${ }^{4}$ Marc Tessier-Lavigne, ${ }^{5}$ Kimberly Scearce-Levie, ${ }^{2} \dagger$ and Robby M Weimer ${ }^{1,2} \dagger$ \\ ${ }^{1}$ Departments of Biomedical Imaging, ${ }^{2}$ Neuroscience, and ${ }^{3}$ Pathology, Genentech Inc., South San Francisco, California 94080 , ${ }^{4}$ Stanford Behavioral and \\ Functional Neuroscience Laboratory, Stanford University, Stanford, California 94305, and ${ }^{5}$ Laboratory of Brain Development and Repair, The Rockefeller \\ University, New York, New York 10065
}

Recent studies implicate death receptor 6 (DR6) in an amyloid precursor protein (APP)-dependent pathway regulating developmental axon pruning, and in a pruning pathway operating during plastic rearrangements in adult brain. DR6 has also been suggested to mediate toxicity in vitro of $\mathrm{A} \beta$ peptides derived from APP. Given the link between APP, $\mathrm{A} \beta$, and Alzheimer's disease (AD), these findings have raised the possibility that DR6 contributes to aspects of neurodegeneration in AD. To test this possibility, we have used mouse models to characterize potential function(s) of DR6 in the adult CNS and in AD-related pathophysiology. We show that DR6 is broadly expressed within the adult $\mathrm{CNS}$ and regulates the density of excitatory synaptic connections onto pyramidal neurons in a genetic pathway with APP. $D R 6$ knock-out also gives rise to behavioral abnormalities, some of which are similar to those previously documented in APP knock-out animals. However, in two distinct APP transgenic models of AD, we did not observe any alteration in the formation of amyloid plaques, gliosis, synaptic loss, or cognitive behavioral deficits with genetic deletion of DR6, though we did observe a transient reduction in the degree of microglial activation in one model. Our results support the view that DR6 functions with APP to modulate synaptic density in the adult CNS, but do not provide evidence for a role of DR6 in the pathophysiology of AD.

Key words: Alzheimer's; APP; DR6

\section{Introduction}

Alzheimer's disease $(\mathrm{AD})$ is a neurodegenerative disorder associated with complex pathology including decreased synaptic density, neurite and neuronal loss, and inflammation (Holtzman et al., 2011). AD is clinically defined by the presence of amyloid plaques comprised primarily of $\mathrm{A} \beta$ peptides, which are $\beta$ - and $\gamma$-secretase generated proteolytic fragments of the amyloid precursor protein (APP; Zhang et al., 2011), suggestive that APP and/or its proteolytic products are causative in human disease. This notion is further supported by human genetic studies that

\footnotetext{
Received Nov. 26, 2013; revised Feb. 19, 2014; accepted Feb. 26, 2014.

Author contributions: W.J.M., A.M.J., M.S., M.T.-L., K.S.-L., and R.M.W. designed research; D.Y.K., W.J.M., A.G., C.E.-N., T.W., M.Y., M.S., and R.M.W. performed research; D.Y.K., W.J.M., A.G., C.E.-N., A.M.J., M.S., K.S.-L., and R.M.W. analyzed data; D.Y.K., W.J.M., A.G., A.M.J., M.T.-L., K.S.-L., and R.M.W. wrote the paper.

This work was fully funded by Genentech, a fully owned subsidiary of Roche. We thank Hilda Solanoy and Heather Kennedy for necropsy support and tissue processing, Hai Ngu, Jeffrey Eastham-Anderson, and Oded Foreman for histopathology analysis, and Kwame Hoyte, Wil Luk, and Yanmei Lu for running A $\beta$ ELISAs.

The authors declare no competing financial interests.

*D.Y.K. and W.J.M. contributed equally and are co-first authors.

tK.S.-L. and R.M.W. contributed equally and are co-senior authors.

Correspondence should be addressed to Dr Robby Weimer, Genentech, Inc., 1 DNA Way, South San Francisco, CA 94080. E-mail: weimer.robby@gene.com.

DOI:10.1523/JNEUROSCI.4963-13.2014

Copyright $\odot 2014$ the authors $\quad 0270-6474 / 14 / 346425-13 \$ 15.00 / 0$
}

identified mutations within $A P P$, or the molecular components that cleave APP, Presenilin 1 and 2, that alter the risk for developing $\mathrm{AD}$ (Cruts et al., 1998; Athan et al., 2001; Rogaeva et al., 2001; Brickell et al., 2007; Hardy and Crook, 2010; Cruchaga et al., 2012; Jonsson et al., 2012). However, our understanding of how APP and its proteolytic products contribute to degeneration remains incomplete, which has led to efforts to identify APPinteracting proteins that mediate neurodegeneration.

Studies of developmentally regulated axon degeneration suggest that death receptor 6 (DR6) may constitute such an APP interacting protein (Nikolaev et al., 2009; Olsen et al., 2014). During development, functional circuits are established through a wave of exuberant neurite outgrowth followed by selective pruning to establish appropriate connectivity (Luo and O'Leary, 2005). Recent studies implicate DR6 and APP in mediating pruning. DR6, also known as TNFRSF21, is a member of the extended tumor necrosis factor receptor superfamily of surface receptors that can engage caspase-mediated signaling (Pan et al., 1998; Kasof et al., 2001). Like APP, DR6 is expressed in neurons during development; further, the pruning of retinal ganglion cell (RGC) axons within their target field is delayed to a similar extent in mice deficient for DR6, APP, caspase-3, or caspase-6 (Nikolaev et al., 2009; Simon et al., 2012; Olsen et al., 2014), implicating DR6 and 
APP in promoting caspase-dependent developmental axon degeneration. In addition, in cell-based binding paradigms APP can bind to the extracellular domain of cell-surface expressed DR6 via its E2 domain (Olsen et al., 2014), suggestive that APP and DR6 may interact to promote developmental axon pruning. DR6 also contributes to axonal pruning in the adult cortex that occurs during plastic rearrangements triggered by sensory deprivation (Marik et al., 2013), though involvement of APP in this process has not yet been described.

DR6 has also been suggested to participate in pathological degeneration. DR6 has been reported to form a receptor complex with $\mathrm{p} 75$ (also a TNFRSF member) required for mediating toxic effects of the $\mathrm{A} \beta$ peptide on cortical neurons in culture (Hu et al., 2013). Together with the role of APP and DR6 in developmental pruning, such studies have raised the possibility that DR6 may contribute to pathological neurodegeneration associated with $\mathrm{AD}$.

Here we have explored whether DR6 and APP functionally interact in the same pathway in vivo to regulate connectivity in the adult nervous system. We have also explored directly whether DR6 contributes to APP-driven pathology by using mouse models of AD.

\section{Materials and Methods}

Animal models. All animal procedures were performed with approval from the Institutional Animal Care and Use Committee in accordance with the institution's ethical guidelines. Unless otherwise stated, all animals are derived within the C57BL/6 murine background, and agematched colony controls were used for comparison between genotypes. DR6 knock-out animals were generated and characterized previously (Zhao et al., 2001). APP knock-out animals were generated by the targeted deletion of the entire APP coding region: deletion from $420 \mathrm{bp}$ upstream of exon 1 through the polyadenylation site. APP;DR6 double knock-out animals were generated by crossbreeding of single knockouts. BACE-1 knock-out animals were described previously (The Jackson Laboratory). The PS2APP (Richards et al., 2003) and APP41 (Rockenstein et al., 2001) transgenic models of AD were generated and characterized previously, and crossed to DR6 knock-out animals. For these experiments, all $P S 2 A P P$ transgenic mice $(P S 2 A P P-T g)$ were maintained as homozygous animals, and behavioral, biochemical, and histological analysis was performed in mice of either sex. PS2APP-Tg;DR6 ${ }^{-1-}$; $G F P-M+$ animals were generated by the crossbreeding of PS2APP-Tg; $D R 6^{-1-}$ animals to animals positive for the GFP-M transgene; a previously characterized reporter line expressing GFP in a subset of neurons (Feng et al., 2000).

In situ hybridization. DR6 mRNA was stained in tissue sections by nonisotropic in situ hybridization as previously described (Ziskin et al., 2013). Briefly, animals were deeply anesthetized, perfused transcardially with $4 \%$ PFA before brains were harvested and fixed overnight in $4 \%$ PFA at $4^{\circ} \mathrm{C}$. Brains were then paraffin embedded and sectioned $(4 \mu \mathrm{m})$ in the coronal plane. Two probes were designed with sizes 901 and $559 \mathrm{nt}$ length, corresponding to oligonucleotides CTGCCCACCTGGAATGTATC to TGGCCGTTGCGGTAGTA and TGTAAAGCTCACACGGACTGTCTGG to TTCGGATACTGCACACCACT of mouse DR6 (Tnfrsf21, GenBank accession NM_178589). Both probes generated comparable staining patterns: data from the 901 nucleotide probe is shown.

Analysis of L2/3 pyramidal cell morphology, spine density, and spine stability. Layer $2 / 3$ pyramidal neurons of the somatosensory cortex were fluorescently labeled by targeted in utero electroporation at embryonic day 16 of progenitor cells that give raise to L2/3 neurons in the adult neocortex, as previously described (Saito and Nakatsuji, 2001), with a CAGGs promoter-based expression plasmid containing the cDNA for the green fluorescent protein EGFP (Gray et al., 2006). At indicated ages, animals of either sex were anesthetized, perfused with $10 \mathrm{ml}$ of PBS followed by $10 \mathrm{ml}$ of $4 \%$ PFA $+10 \%$ sucrose in PBS and the collected brains fixed in $4 \% \mathrm{PFA}+10 \%$ sucrose in PBS overnight at $4^{\circ} \mathrm{C}$. Postfixation, brains were embedded in agarose and immersed with PBS. Apical dendrites from fluorescently labeled L2/3 pyramidal neurons were visualized en bloc using a two-photon microscope (Prairie Technologies Ul- tima IV microscope powered by a Spectra Physics MaiTai DeepSee laser). To assess gross dendritic arbor structure, neuronal cell bodies and their processes were imaged under a $60 \times$ NA 1.0 objective (Olympus) at a field-of-view of $1024 \times 1024$ pixels at $0.122 \mu \mathrm{m}$ /pixel and $z$-axial step size of $1 \mu \mathrm{m}$ using $910 \mathrm{~nm}$ laser wavelength. Dendritic arbor morphology was quantified using Neurolucida (MBF Bioscience) to trace dendritic processes and NeuroExplorer to perform Sholl analysis, using 20- $\mu \mathrm{m}$-radius spheres. shRNA-mediated knockdown of APP or DR6 was achieved using a CAGGs-based plasmid expressing the fluorescent protein mCherry by placing an APP (5' ACA CGG AGG TGT GTC ATA ACC GTT TTG GCC ACT GAC TGA CGG TTA TGA CAC CTC CGT GT) or DR6 (Olsen et al., 2014) targeting sequence into the mir155 3'UTR sequence following the mCherry cDNA; the mir 155 sequence mediates efficient processing of hairpin RNA (Shan et al., 2009). The DR6-expression plasmid was generated by subcloning a cDNA encoding full-length murine DR6 into the CAGGs-based expression plasmid. Individual dendritic spines on apical dendrites were visualized using $910 \mathrm{~nm}$ laser wavelength and a $40 \times$ NA 0.8 objective (Olympus) with a field-of-view of $512 \times 512$ pixel at $0.084 \mu \mathrm{m} /$ pixel and $z$-axial stepping of $1 \mu \mathrm{m}$. Coelectroporation of mCherry expressing plasmids was confirmed using an overlapping laser beam tuned to $1020 \mathrm{~nm}$. Dendritic spine density was quantified using custom analysis routines in MATLAB (MathWorks) and represented per animal as the average number of spines $(\sim 100-200$ spines counted from each neuron) per $\mu \mathrm{m}$ of dendrite analyzed from 3 to 5 neurons located within the somatosensory cortex.

The stability of spines on L2/3 apical dendrites within the somatosensory neocortex was assessed via longitudinal in vivo imaging of dendrites and spines, as described previously (Holtmaat et al., 2009), with minor modifications. Cranial imaging windows were implanted into male or female adult ( $\sim 2$ months of age) animals 2 weeks before initiating an imaging experiment. For imaging, animals were anesthetized ( $3 \%$ sevoflurane, $2 \mathrm{~L} / \mathrm{min}$ flow rate), immobilized on a custom built heated stage and apical dendrites of L2/3 pyramidal neurons, transfected by in utero electroporation with a CAGGs-based expression plasmid encoding the fluorescent protein DsRedExpress (Bevis and Glick, 2002), were visualized using $980 \mathrm{~nm}$ laser wavelength and a $40 \times$ NA 0.8 objective (Olympus) with a field-of-view of $512 \times$ 512 pixel at $0.084 \mu \mathrm{m} /$ pixel and $z$-axial stepping of $1 \mu \mathrm{m}$. The spatial location of individual dendritic segments were mapped relative to unique fiducial markers in the pia mater vasculature, thus enabling the identification and tracking of spines across time points. A dendritic spine was defined as persistent if it was detected in both the initial and 2 week imaging time points. The proportion of spines that persisted (survived) over 2 weeks was estimated by dividing the number of persistent spines by the total number of spines detected on the corresponding dendritic segment at the initial time point, and is reported as an average across animals per genotype. Similar to previous results, $\sim 20-30 \%$ of dendritic spines were lost over a 2 week interval (Holtmaat et al., 2009); however, spine density at the initial and 2 week time point did not differ (data not shown).

Barnes maze. The maze consists of an elevated $(90 \mathrm{~cm})$ white circular table ( $91 \mathrm{~cm}$ diameter) with twenty $5 \mathrm{~cm}$ holes equally spaced around the perimeter of the maze (Stoelting). A target escape tunnel $(6 \times 25 \mathrm{~cm})$ was placed below one of the holes. The maze was placed in the center of a room with prominent extramaze visual cues. During all phases of training, mice were released from a cylinder in the center of the maze, as bright lights were turned on. Once the mouse entered the escape tunnel, the lights were dimmed, and the mouse was allowed to stay in the tunnel for $10-20 \mathrm{~s}$. Mice that failed to reach the goal within the time limit were gently guided to the escape box and left inside for 10-20 s. During familiarization training, a channel was made such that only one escape hole was available for the animal to enter. Mice received four consecutive trials ( 1 min $\max$ ) to become familiar with entering the escape tunnel. Spatial training consisted of allowing the mouse to freely explore the maze for up to 3 min to locate the new target hole. During this time, the animal's movements were recorded using a ceiling mounted camera and tracked using TopScan software (CleverSys). Training occurred over 2 consecutive days, with four trials per day separated by a $15 \mathrm{~min}$ intertrial interval. Latency to enter target hole, distance traveled, velocity $(\mathrm{m} / \mathrm{s})$, and errors (total number of nose pokes into incorrect holes) were analyzed. A spatial probe trial was conducted $24 \mathrm{~h}$ after the final training session, where the 
escape tunnel was removed and the animal was allowed to explore for 3 min. Number of nose pokes and percentage time spent exploring each hole, as well as latency and path length to reach the virtual target hole were measured. A measure of percentage accuracy was calculated [(percentage time exploring target hole/ all locations) $\times 100]$.

Water maze. For PS2APP-Tg mice, the water maze consisted of a pool (122 cm diameter) filled with water $\left(18 \pm 2^{\circ} \mathrm{C}\right)$ made opaque with nontoxic white tempera paint, and placed in a room surrounded by distinct extramaze cues. Mice were first given four pretraining trials in which they had to swim down a channel $(15 \times 122 \mathrm{~cm})$ and mount a $15 \mathrm{~cm}$ platform hidden $1.5 \mathrm{~cm}$ below the water surface at the end of the channel. During hidden platform training, mice swam freely throughout the pool for $60 \mathrm{~s}$ to locate the submerged platform. Two sessions ( 3 trials, 10 min intertrial interval) of hidden training occurred on each of 5 consecutive days. The platform location remained the same throughout the hidden-platform training, but the drop location was changed semirandomly between trials. Mice that did not find the platform within $60 \mathrm{~s}$ were guided to it and placed on it for $10 \mathrm{~s}$. A spatial probe trial was performed $72 \mathrm{~h}$ after completion of hidden-platform training. The platform was removed, and mice were allowed to swim in the pool for $60 \mathrm{~s}$. For cued visibleplatform training, the platform was submerged but visibly cued with a striped mast (15 cm in height). Mice received three cued sessions, each consisting of two training trials with an intertrial interval of $10 \mathrm{~min}$. Platform location and drop location were varied for each cued trial. Escape latencies, swim paths, swim speeds, percentage of time spent in each quadrant, and platform crossings (in a zone $200 \%$ the size of the platform) were recorded using a ceiling-mounted camera and tracked using TopScan software (CleverSys).

To demonstrate that behavioral effects are independent of exact model, testing location, or exact protocol, APP41 mice were tested by a different lab in a different facility as previously described (Faizi et al., 2012). The Morris Water Maze used for APP41 mice was surrounded by privacy blinds on which visual cues were placed. Male and female APP41 mice (6-7 months of age) received a daily series of four trials, $\sim 45 \mathrm{~min}$ apart. To verify the visual acuity of mice, animals were tested in four trials during which the platform was made visible. The probe trial was conducted $24 \mathrm{~h}$ after the last hidden trial. Each trial was recorded through an overhead camera and the tracking software EthoVision (Noldus Information Technology). Otherwise testing procedure was similar to that used for the PS2APP-Tg model.

Active avoidance. Avoidance boxes $(44 \times 17 \times 25 \mathrm{~cm})$, which consisted of two compartments separated by an automated guillotine door (Med Associates), were located in separate sound-attenuating cubicles. Mice received 2 consecutive days of avoidance training following a modified protocol (Foldi et al., 2011). Mice acclimated for $30 \mathrm{~min}$ in a room adjacent to the training room. Each training session began with a $5 \mathrm{~min}$ acclimation period where the animal was placed into one side of the shuttle box with the door closed and no stimuli presented. Avoidance training trials started immediately following this acclimation period. The door between the two sides of the shuttle box opened and a light and $72-73 \mathrm{~dB}$ tone was presented for a total of $7 \mathrm{~s}$ on the side of the chamber that contained the animal, and was coterminated with a $2 \mathrm{~s}$ foot shock $(0.3 \mathrm{~mA})$, after which the door closed. If the animal shuttled during the tone/light presentation, the stimulus was terminated immediately, the shock was not delivered; this was scored as an avoidance response. If the animal shuttled during the foot shock presentation, the shock was immediately terminated and the door closed; this was recorded as an escape response. The animal received 100 consecutive trials each day, with varying intertrial intervals averaging $40 \mathrm{~s}$. Stimulus delivery and avoidance responses were controlled and recorded automatically using the MED-PC IV software (Med Associates).

Fear conditioning. Mice were placed in a fear-conditioning chamber $(31.8 \times 25.4 \times 26.7 \mathrm{~cm}$; (Med Associates) within a sound-attenuating cubicle. The mice were allowed to explore the chamber for $180 \mathrm{~s}$ before a $30 \mathrm{~s}$ tone ( $90 \mathrm{~dB}$ white noise) was presented, which coterminated with a $2 \mathrm{~s}$ foot shock $(0.7 \mathrm{~mA})$. There was then a $90 \mathrm{~s}$ delay followed by a second pairing of a $30 \mathrm{~s}$ tone with a $2 \mathrm{~s}$ foot shock, and then another $90 \mathrm{~s}$ delay. Twenty-four hours following training, a context test was administered. Mice were placed into the same chamber used for training and their freezing behavior was monitored for $5 \mathrm{~min}$. No shock or tone was ad- ministered. After a $4 \mathrm{~h}$ delay, a cued test was administered. For this, the testing chamber was cleaned with $1 \%$ acetic acid solution to provide a novel olfactory cue. The floor of the chamber was covered with a smooth Plexiglas plate and a semicircle insert was added to alter the context of the environment. The house lights in the conditioning box were turned off. Mice were placed in different chambers from the ones used during training/context testing. Mice had $180 \mathrm{~s}$ to explore the new altered context before the tone used in training was presented continuously for $180 \mathrm{~s}$. Freezing to new context and during the tone was monitored. The behavior of the mice during training and testing phases were recorded using a near infrared camera and the percentage time freezing was calculated using Video Freeze software (Med Associates).

Open field. Spontaneous locomotor activity was measured with an automated Photobeam Activity System-Open Field (San Diego Instruments). Mice were placed individually in a clear plastic chamber $(41 \times$ $41 \times 30 \mathrm{~cm}$ ), and their horizontal and vertical movements were monitored for $15 \mathrm{~min} / \mathrm{session}$ with two $16 \times 16$ photobeam arrays. Mice were tested every other day for a total of three sessions.

$A \beta E L I S A$ and histological analysis of PS2APP and APP41 animals. Mice were deeply anesthetized and transcardially perfused with PBS. The brain was collected and split along the midline. The right hemi-brain was drop fixed for $48 \mathrm{~h}$ at $4^{\circ} \mathrm{C}$ in $4 \%$ paraformaldehyde for immunohistochemistry (see below), and the left forebrain was frozen and later homogenized in 10 volumes of $5 \mathrm{~m}$ guanidine $\mathrm{HCl}$ in $50 \mathrm{~mm}$ Tris, $\mathrm{pH} 8.0$, and further diluted 1:10 in casein blocking buffer $[0.25 \%$ casein, $0.05 \%$ sodium azide, aprotinin (20 $\mathrm{mg} / \mathrm{ml}), 5 \mathrm{~mm}$ EDTA, pH 8.0, leupeptin $(10 \mathrm{mg} / \mathrm{ml})$ in PBS] for A $\beta 40$ and A $\beta 42$ analysis, as previously described (Atwal et al., 2011).

Immersion-fixed hemi-brains were cryoprotected, frozen, and sectioned at $35 \mu \mathrm{m}$ as previously described (Wang et al., 2011). Up to 40 hemi-brains were embedded per block in a solid matrix and sectioned coronally (MultiBrain processing by NeuroScience Associates). Sections were stored in cryoprotectant at $-20^{\circ} \mathrm{C}$ until use. Free-floating sections were then rinsed in Tris-buffered saline (TBS), treated with hydrogen peroxide in TBST (TBS plus Triton X-100), and blocked with TBST plus goat serum before overnight incubation at room temperature with primary antibody diluted in TBST (Wako rabbit, Rb; anti-IBA1, 019-19741, 1:15,000; Serotec biotinylated rat anti-CD68, MCA1957BT, 1:400; or Dako rabbit, Rb; anti-GFAP, Z0334, 1:20,000). Binding was detected with biotin-conjugated secondary antibodies followed by avidin-biotinHRP complex (details in Vectastain elite ABC kit, Vector Laboratories), and developed with diaminobenzidine tetrahydrochloride. The IBA1 and CD68-immunostained sections were counterstained with a Nissl stain $(0.05 \%$ thionine $/ 0.08 \mathrm{~m}$ acetate buffer, $\mathrm{pH} 4.5)$. To reveal amyloid plaque pathology, neighboring sections were stained by CampbellSwitzer stain. A detailed protocol for this stain can be found online at the NeuroScience Associates website (http://www.neuroscienceassociates. com/Documents/Publications/campbell-switzer_protocol.htm).

Histological samples were imaged at $100 \times$ magnification using the Leica SCN400 system or DM6000B microscope equipped with automated loader and software (Leica Microsystems). Quantification of GFAP, CD68, and IBA1 staining and enlarged dark cluster areas was performed using morphometric-based methods in MATLAB (MathWorks), as previously described (Le Pichon et al., 2013). Plaque area was analyzed from slides stained using the Campbell-Switzer method with plaques appearing with a black or amber hue. Multiple color classifiers spanning narrow ranges in RGB space were created for positive and negative features. Plaques were segmented using these classifiers and applying adaptive thresholding, Euclidean distance transform, morphological operations, and reconstruction. The percentage plaque load or IBA1/GFAP/CD68 positivity for the entire section was calculated by normalizing the positive pixel area to tissue section area and averaged from four to seven sections/animal. All images, segmentation overlays, and data were reviewed by a pathologist.

Analysis of dendritic spine density relative to amyloid plaques. GFP-M transgenic animals, of either sex, of indicated PS2APP-Tg and DR6 genotypes were injected $(10 \mathrm{mg} / \mathrm{kg})$ with an amyloid probe, methoxyX04 (Klunk et al., 2002), $24 \mathrm{~h}$ before brain harvest. Apical dendrites of L5 pyramidal neurons and amyloid plaques within the somatosensory cortex were imaged en bloc using a two-photon microscope (Prairie Technologies Ultima IV microscope powered by two Spectra Physics 
MaiTai DeepSee laser). Individual dendrites and spines were visualized under a $60 \times \mathrm{NA}$ 1.0 objective (Olympus), with a field-of-view $1024 \times 1024$ pixels at $0.098 \mu \mathrm{m} /$ pixel and $z$-axial step size of $0.5 \mu \mathrm{m}$, using $910 \mathrm{~nm}$ laser wavelength and 525/50 $\mathrm{nm}$ bandpass filter (Chroma) placed before the GaAsP detector. Simultaneous imaging of dendrites and amyloid plaque was achieved by tuning a second beam-overlapping laser to $840 \mathrm{~nm}$ wavelength, separating green and blue fluorescent photons with a 495 LP dichroic mirror (Chroma) and placing a 440/80 $\mathrm{nm}$ bandpass filter before an independent detector. Spine density was calculated as the number of visible spines on an apical dendrite divided by the corresponding length of dendrite per field-of-view. A dendrite was considered to be proximal to an amyloid plaque if an amyloid plaque was in the field-ofview. A dendrite considered distal to amyloid plaque was confirmed to be at least $100 \mu \mathrm{m}$ away from the nearest plaque in $x, y$, or $z$ dimensions. For each class of dendrites, proximal and distal spine density was measured from three to five neurons per animal, representing 100-200 spines counted per neuron and reported as the average per animal. Amyloid plaque density was assessed over the same cortical area imaged for spine measurements; however, a lower-magnification was used to capture greater cortical volume $(\sim 400 \times 400 \times 200$ $\mu \mathrm{m})$ with a $20 \times$ NA 1.0 objective (Olympus). Individual plaques were identified as a cluster of pixels with intensity values three times greater than background and at least $50 \mu \mathrm{m}^{3}$ in volume. Plaque density was calculated per animal as the total number of plaques divided by imaged volume. Plaque size was calculated as the average volume per plaque per animal.

Statistical analysis. All data are presented as mean \pm SEM. For quantitative cell morphology (apical dendrite morphology and spine density), biochemical, and histological analysis, statistical significance was assessed by Student's $t$ test for comparison between two samples, or one-way ANOVA with post hoc Tukey-Kramer HSD test for comparison across multiple groups. Unless otherwise stated, for comparison of behavioral data collected over multiple sessions or positions (water maze), we used multifactor repeated-measures ANOVA with between-subjects factor of genotype (PS2APP or DR6) and the within-subjects factor of sessions (sessions or trials) or quadrants (platform positions). Sex was also included as a between-subjects factor in the analysis; however, there was no genotype effect specific for a given sex, thus all data are pooled based on genotype. One-way ANOVA with post hoc Tukey-Kramer HSD or Dunnett's test were performed for comparison with control animals. In all cases, $\mathrm{n} / \mathrm{s}$ corresponds to not significant, $p>0.05 ;{ }^{\star} p \leq 0.05,{ }^{* *} p \leq 0.01$, and ${ }^{* * *} p \leq 0.001$.

\section{Results}

DR6 is widely expressed in the adult CNS

Before investigating the functional role of DR6 in the mature nervous system, we first confirmed that it is expressed by charac-
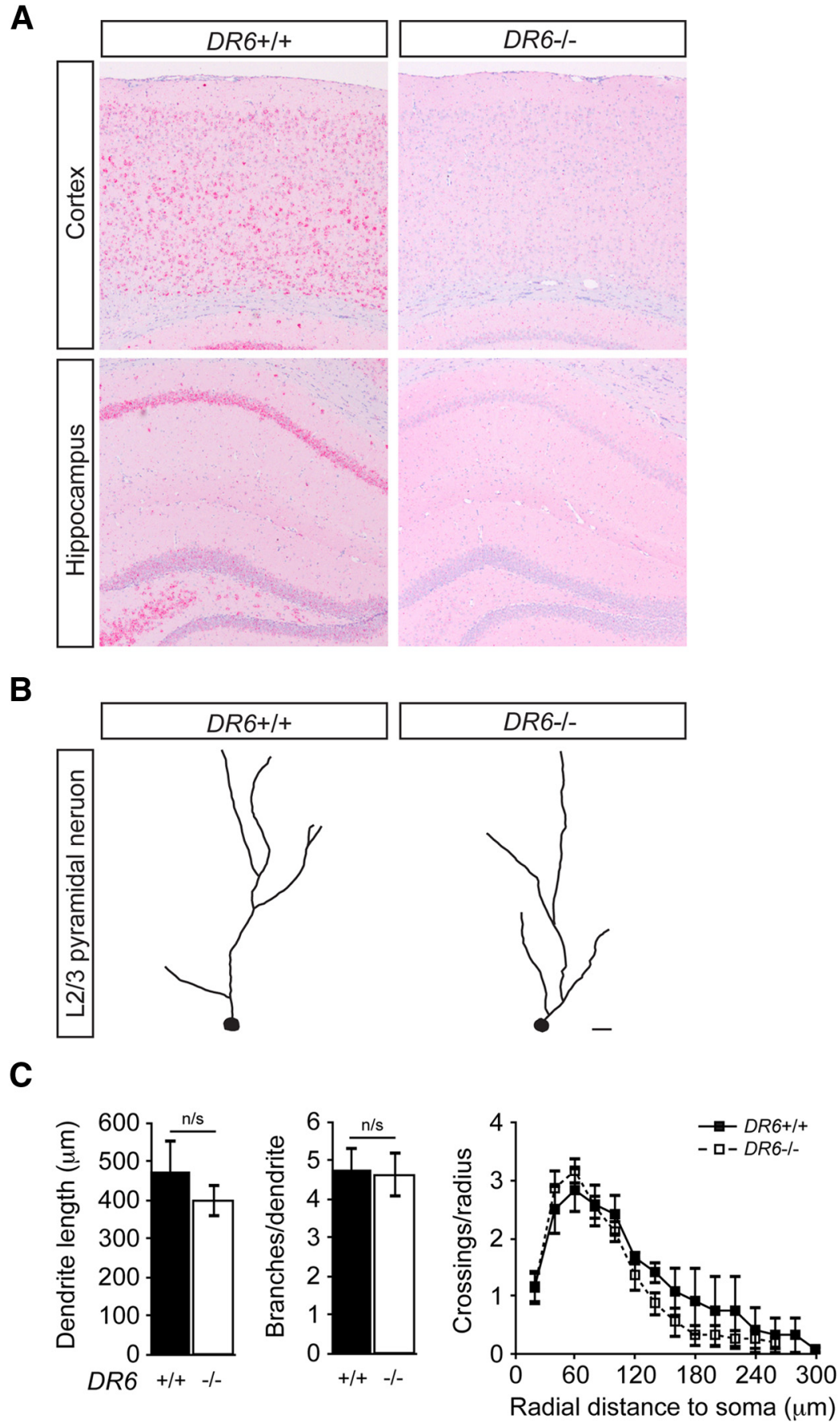

Figure 1. DR6 is broadly expressed in the adult CNS but is not required to establish gross neuronal morphology. $\boldsymbol{A}$, In situ hybridization of coronal sections shows wide expression of DR6 mRNA in L2-L6 of the neocortex and the molecular layer in the hippocampus in $D R 6^{+1+}$ animals, which is absent in $D R 6^{-1-}$ animals. $B$, Representative traces corresponding to apical dendrites of $L 2 / 3$ pyramidal neurons labeled by in utero electroporation of a GFP-expressing plasmid in DR6 ${ }^{+1+}$ and $D R 6^{-1-}$ animals. Scale bar, $20 \mu \mathrm{m}$. C, Quantification of the total apical dendrite length, the number of branches per apical dendrite and the complexity of apical dendrites, measured as the number of dendrite crossings per $20 \mu \mathrm{m}$ spherical radii increments, for $L 2 / 3$ pyramidal neurons in $D R 6^{+/+}$versus $D R 6^{-1-}$ animals, $n=4$ and 5 animals, respectively, with three neurons analyzed per animal.

terizing DR6 mRNA localization in 2-month-old $D R 6^{+/+}$and $D R 6^{-1-}$ animals using in situ mRNA hybridization. Staining of coronal brain sections in $D R 6^{+/+}$revealed broad expression of DR6 mRNA absent in DR6 ${ }^{-1-}$ animals. Specifically, DR6 mRNA expression is evident within neocortical L2-L6, in the pyramidal cell layers (CA1-3 region) of the hippocampus proper and gran- 
A

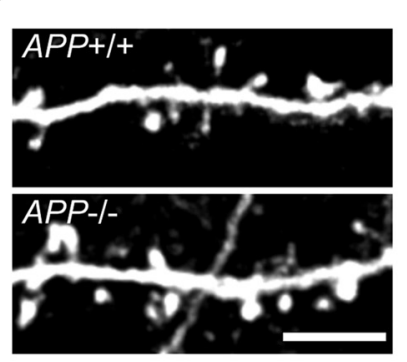

C

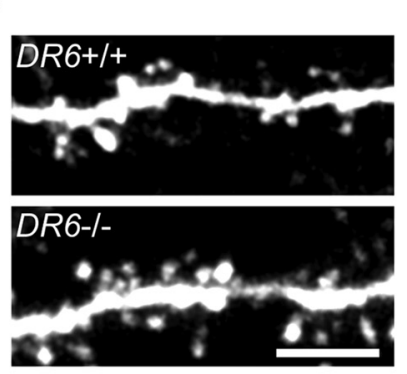

E

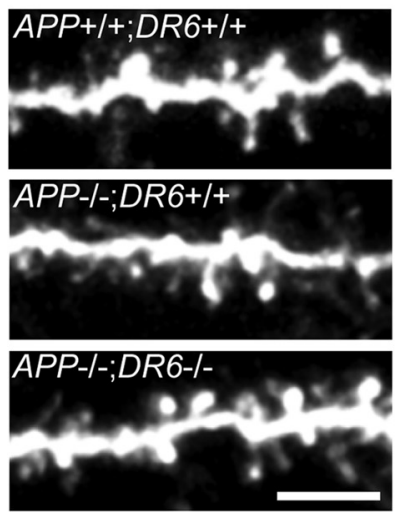

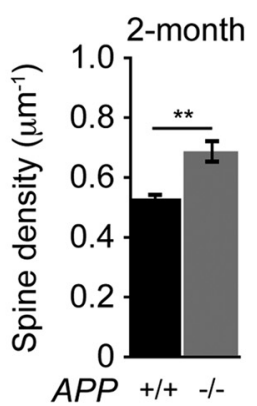

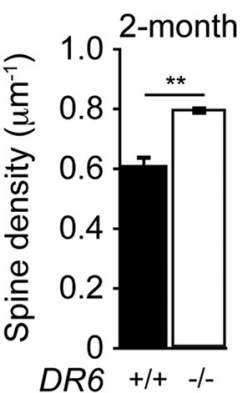

B

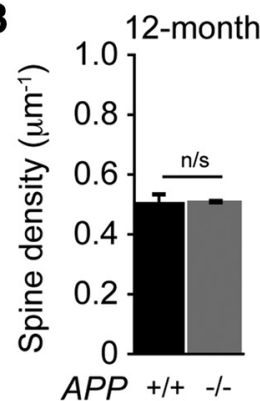

D

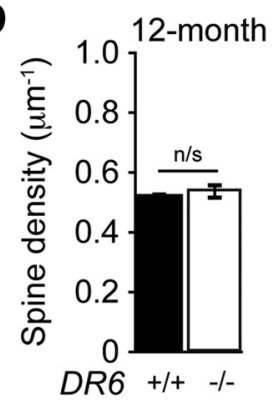

$\mathbf{F}$

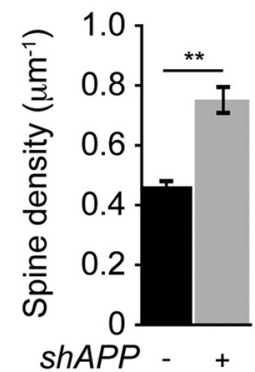

G

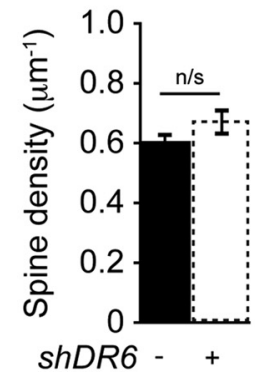

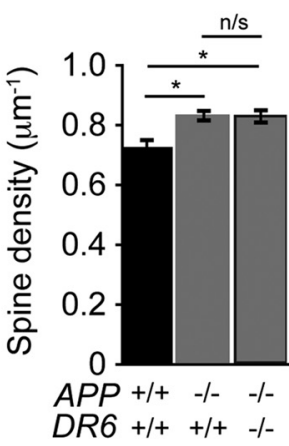

H

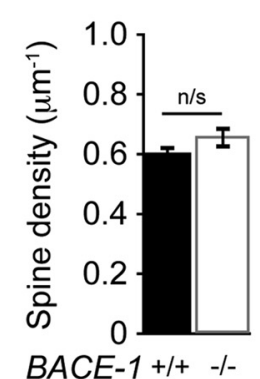

Figure 2. DR6 and APP define a genetic pathway that regulates synapse density independent of BACE-1 activity. $\boldsymbol{A}$, Representative images and quantitation of spine density on apical dendrites from $2-$ month $A P P^{+/+}$and $A P P^{-1-}$ animals. Dendritic spine density is significantly increased in $A P P^{-1-}$ animals compared with $A P P^{+1+}\left(A P P^{+1+}, 0.53 \pm 0.03, n=7 ; A P P^{-1-}, 0.68 \pm\right.$ 0.02 spines $/ \mu \mathrm{m}, n=5$ animals). $B$, Spine density in 12 -month $A P P^{+/+}$and $A P P^{-/-}$animals $\left(A P P^{+/+}, 0.50 \pm 0.04, n=5\right.$; $A P P^{-1-}, 0.51 \pm 0.01$ spines $/ \mu \mathrm{m}, n=3$ animals). C, Representative images and quantitation of spine density on apical dendrites from 2-month $D R 6^{+1+}$ and $D R 6^{-1-}$ animals. Dendritic spine density is significantly increased in $D R 6^{-1-}$ animals compared with DR6 ${ }^{+/+}\left(D R 6^{+1+}, 0.61 \pm 0.04, n=3 ; D R 6^{-1-}, 0.79 \pm 0.02\right.$ spines $/ \mu \mathrm{m}, n=3$ animals). D, Spine density in 12 -month $D R 6^{+/+}$and $D R 6^{-1-}$ animals $\left(D R 6^{+/+}, 0.52 \pm 0.01, n=6 ; D R 6^{-1-}, 0.54 \pm 0.03\right.$ spines $/ \mu \mathrm{m}, n=9$ animals). E, Representative images and quantitation of spine density on apical dendrites from 2 -month $A P P{ }^{+1+} ; D R 6^{+1+}, A P P^{-1-} ; D R 6^{+1+}$ and $A P P^{-1-} ; D R 6^{-1-}$ animals. Dendritic spine density is significantly increased in $A P P^{-1-} ; D R 6^{+1+}$ and $A P P^{-1-} ; D R 6^{-1-}$ animals compared with $A P P^{+1+} ; D R 6^{+/+}$; however, there is no difference between $A P P^{-1-} ; D R 6^{+1+}$ and $A P P^{-1-} ; D R 6^{-1-}$ animals $\left(A P P^{+1+} ; D R 6^{+1+}, 0.73 \pm 0.02, n=6 ; A^{\prime} P^{-1-} ; D R 6^{+1+}, 0.83 \pm 0.03, n=4 ; A P P^{-1-} ; D R 6^{-1-}, 0.83 \pm 0.03\right.$ spines/ $\mu \mathrm{m}, n=4$ animals). $\boldsymbol{F}$, Quantitation of spine density on apical dendrites from 1-month wild-type animals expressing shRNA targeting APP (shAPP +) or a nonspecific shRNA targeting LacZ (shAPP-). Knockdown of APP increased spine density

ule cell layer of the dentate gyrus (Fig. 1A). The pattern of mRNA expression within these brain regions suggests that DR6 is expressed within pyramidal neurons of the mature cortex. Expression is also found in the hilus of the dentate gyrus, the amygdala, thalamus, brainstem, and cerebellum, consistent with expression of DR6 in other cell types. However, expression of DR6 in white matter was below the limit of detection using these methods.

While collecting brain samples from $D R 6^{+/+}$and $D R 6^{-1-}$ animals for expression analysis, we did observe a trend toward an increase $(\sim 10 \%)$ in the weight of whole brains from $D R 6^{-1-}$ compared with $D R 6^{+/+}$animals $\left(D R 6^{+/+}\right.$male, $0.451 \pm 0.010, n=7 ; D R 6^{-1-}$ male, $0.486 \pm 0.004, n=5, p<0.01 ; D R 6^{+/+}$ female, $0.457 \pm 0.003, n=3 ; D R 6^{-1-}$ females, $0.49 \pm 0.016 \mathrm{~g}, n=4$ animals, $p=$ $0.06)$. Consistent with this observation, a similar $(\sim 10 \%)$ increase in brain size was observed in $D R 6^{-/-}$compared with $D R 6^{+/+}$animals in an independent study using $\mu$ CT-based imaging to measure whole brain volume (data not shown). However, comparison of the gross organization (apparent laminar organization and thickness) of the cortex, hippocampus, as well as other brain regions, in coronal sections counterstained with hematoxylin did not reveal an obvious difference between $D R 6^{+/+}$and $D R 6^{-/-}$ animals at 2 months of age. To further examine whether loss of DR6 function alters gross cellular architecture, we assessed the morphology of L2/3 pyramidal neurons fluorescently labeled by in utero electroporation. In both $D R 6^{+/+}$and $D R 6^{-l-}$ animals, the cell bodies of labeled neurons were positioned within $300 \mu \mathrm{m}$ of the neocortical surface (data not shown), consistent with the labeling and correct positioning of L2/3 pyramidal neurons. Morphometric analysis of total dendritic length, branch number, and complexity did not reveal a difference between $D R 6^{-/-}$compared with $D R 6^{+/+}$

$\leftarrow$

(shAPP- $0.46 \pm 0.03, n=5 ;$; $h A P P+, 0.75 \pm 0.05$ spines/ $\mu \mathrm{m}, n=4$ animals). $G$, Quantitation of spine ensity on apical dendrites from 2-month wild-type animals expressing shRNA targeting DR6 (shDR6+) or a nonspecific shRNA targeting LaCZ (shDR6-). Knockdown of DR6 did not alter spine density (shDR6- $0.60 \pm 0.03, n=6 ;$; $h D R 6+, 0.67 \pm 0.05$ spines/ $\mu \mathrm{m}, n=6$ animals). $\boldsymbol{H}$, Quantitation of spine density on apical dendrites from 2-month $B A C E-1^{+/+}$and $B A C E-1^{-1-}$ animals. Loss of BACE-1 function does not result in altered spine density $\left(B A C E 1^{+/+}, 0.60 \pm 0.02, n=7 ; B A C E-1^{-1-}\right.$, $0.66 \pm 0.04$ spines $/ \mu \mathrm{m}, n=7$ animals). Scale bars: $A, C, E, 5$ $\mu \mathrm{m}$. 
animals (Fig. $1 B, C$ ), suggesting that DR6 function is not required for establishing or maintaining gross neuronal architecture. The basis for the larger mass of DR6 knock-out brains compared with wildtypes is not clear, although it could potentially reflect reduced pruning of axons and neuronal cell bodies (Marik et al., 2013), or changes in brain vasculature (Tam et al., 2012).

DR6 and APP define a genetic pathway independent of BACE-1 that regulates excitatory synapse density

Recent studies of developmental axon pruning suggest that DR6 and APP may function in the same pathway to regulate axonal morphology in the retinotectal system (Nikolaev et al., 2009; Olsen et al., 2014). Loss of APP function has been reported to result in an increase in excitatory synapse density in the cortex of adult animals (Priller et al., 2006), evidenced by an increase in the number of dendritic spines on apical dendrites of pyramidal neurons in the neocortex (Bittner et al., 2009). To assess whether DR6 may act with APP in the mature nervous system, we examined whether the loss of DR6 phenocopies the loss of APP by quantifying dendritic spines on L2/3 pyramidal neurons within the somatosensory cortex fluorescently labeled by in utero electroporation.

To establish a baseline for comparison, we characterized spine density in $A P P^{+/+}$ versus $A P P^{-1-}$ animals at 2 months of age. Similar to published analysis of L5 pyramidal neurons in $A P P^{-1-}$ animals (Bittner et al., 2009), apical dendrites of L2/3 pyramidal neurons exhibit a $\sim 30 \%$ increase in spine density compared with $A P P^{+/+}$animals (Fig. $2 A$ ). This increase in spine density is transient: analysis of spine density on L2/3 pyramidal neurons at 12-months of age did not reveal a difference between $A P P^{-1-}$ and $A P P^{+/+}$animals (Fig. $2 B)$. Furthermore, longitudinal in vivo imaging of dendritic spines in 2-month $A P P^{-1-}$ and $A P P^{+/+}$animals did not reveal a difference in spine stability between genotypes, as assessed by quantifying the proportion of spines that persisted over a 2 week interval $\left(A P P^{+/+}, 0.72 \pm 0.03, n=5\right.$ animals, 18 neurons, 742 spines $_{t=0} ; A P P^{-1-}$, $0.77 \pm 0.04, n=3,8,374)$, consistent with previously published observation of L5 neurons (Bittner et al., 2009), suggesting that loss of APP does not directly alter spine dynamics even though spine density is increased.

In $D R 6^{-/-}$animals, similar to $A P P^{-1-}$ animals, spine density was increased
A

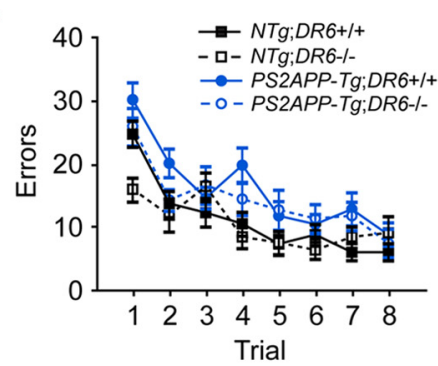

B

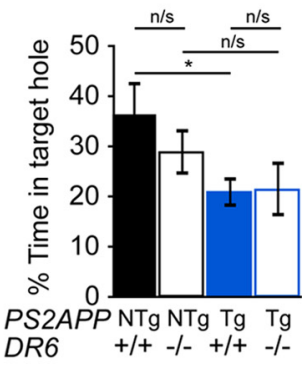

C

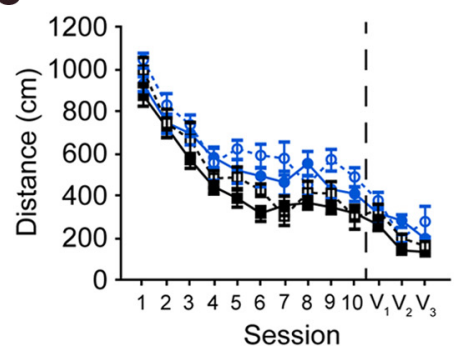

D

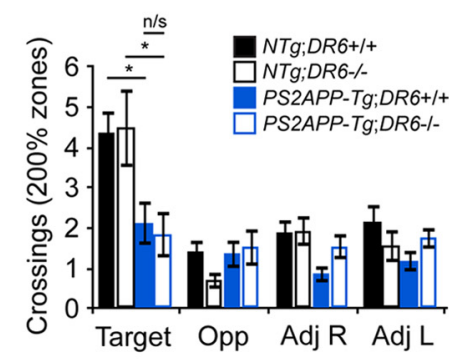

E

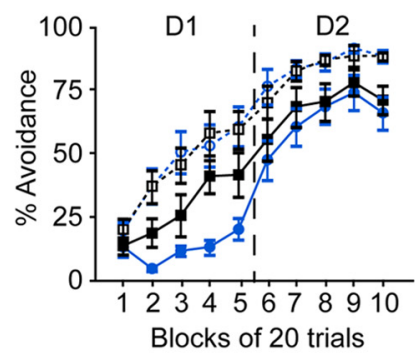

$\mathbf{F}$

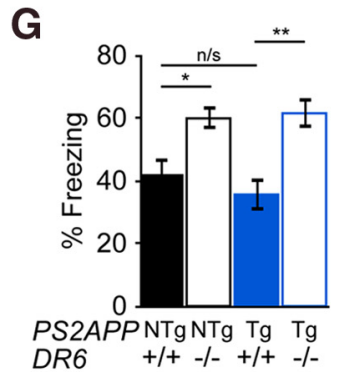

H
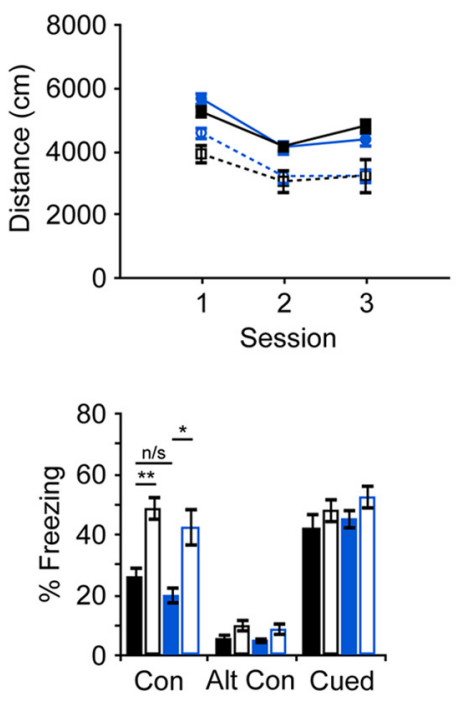

Figure 3. Loss of DR6 function does not ameliorate spatial or conditioned learning and memory deficits in 7- to -8-month-old PS2APP mice. $A$, The number of errors made (nose pokes into the incorrect hole) before reaching the target hole in the Barnes Maze. PS2APP, but not DR6, genotype significantly altered animal performance ( $p<0.001$, two-way repeated-measures ANOVA). $\boldsymbol{B}$, Percentage time spent searching the former target/all hole locations in a Barnes Maze probe trial conducted $24 \mathrm{~h}$ after the last training trial. PS2APP, but not DR6, genotype significantly altered animal performance $(p<0.05$, two-way ANOVA); $n=20$ $N T g ; D R 6^{+/+}, 18 N T g ; D R 6^{-1-}, 19 P S 2 A P P-T g ; D R 6^{+/+}$and 14PS2APP-Tg;DR6 ${ }^{-1-}$ mice. C, The distance traveled before reaching the hidden (1-10) or visible $\left(\mathrm{V}_{1-3}\right)$ platform during each training session of the Morris Water Maze. PS2APP, but not DR6, genotype significantly altered animal performance during the hidden platform training $(p<0.001)$ and visible platform training $(p<0.01$, two-way repeated-measures ANOVA). $\boldsymbol{D}$, The number of times mice crossed over an area $200 \%$ greater than the previous platform location, compared with similar control locations in other quadrants during a probe trial conducted $72 \mathrm{~h}$ after Morris Water Maze training. PS2APP, but not DR6, genotype significantly altered crossing in the target zone ( $p<0.001$, two-way ANOVA); target, opposite (Opp), adjacent right (Adj R), and adjacent left (Adj L); $n=19$ NTg;DR6 ${ }^{+/+}, 14 \mathrm{NTg;DR6^{-/- }}, 16$ PS2APP-Tg;DR6 ${ }^{+/+}$and 13 PS2APP-Tg;DR6 ${ }^{-1-}$ mice. $E$, Active avoidance training measured as a percentage of trials (in blocks of 20 trials, with multiple blocks per day, D) where an avoidance response occurred; $n=10$ mice/group. DR6 genotype had a significant effect on avoidance rates on both $\boldsymbol{E}, \mathbf{D 1}(p<0.001)$ and $\boldsymbol{E}, \mathbf{D 2}(p<0.01$, two-way repeated-measures ANOVA), but there was no effect of or interaction with PS2APP genotype. $F$, Total distance traveled in an open field during three 15 min sessions; $n=20$ mice/group. DR6 genotype significantly reduced animal activity ( $p<0.001$, two-way repeated-measures ANOVA), but there was no effect of or interaction with PS2APP genotype. G, Percentage time freezing at the end of fear conditioning training. DR6 genotype had a significant effect on freezing behavior ( $p<0.0001$, two-way ANOVA), but there was no effect of or interaction with PS2APP genotype. $\boldsymbol{H}$, Percentage time freezing to the training context $24 \mathrm{~h}$ after training, and to an altered context and in response to a cue $28 \mathrm{~h}$ after training. DR6 genotype had a significant effect on freezing behavior to the context $(p<0.0001$, two-way ANOVA), but there was no effect of or interaction with PS2APP genotype; $n=20 \mathrm{NTg}_{\mathrm{DRO}}{ }^{+/+}, 19 \mathrm{NTg} ; \mathrm{DR6}^{-1-}, 18$ PS2APP-Tg;DR6 ${ }^{+1+}$ and 16 PS2APP-Tg;DR6 ${ }^{-1-}$ mice. 
$\sim 30 \%$ on apical dendrites of $\mathrm{L} 2 / 3$ pyramidal neurons at 2 months of age (Fig. 2C). This increase in spine density was also transient, as spine density did not differ between 12-month $D R 6^{-1-}$ and $D R 6^{+/+}$animals (Fig. 2D). Furthermore, longitudinal in vivo imaging of dendritic spines in 2-month $D R 6^{+/+}$, $D R 6^{+/-}$, or $D R 6^{-1-}$ animals did not reveal a difference in spine stability between genotypes, as assessed by quantifying the proportion of spines that persisted over a 2 week interval $\left(D R 6^{+/+}\right.$, $0.75 \pm 0.02, n=6$ animals, 19 neurons, 1696 spines $_{t=0} ; D R 6^{+/-}$, $0.72 \pm 0.02, n=5,14,992 ; D R 6^{-/-}, 0.74 \pm 0.01, n=5,16$, 1838). Interestingly, there was evidence of a DR6 gene dose dependence in spine density $\left(D R 6^{+/+}, 0.55 \pm 0.02, n=6 ; D R 6^{+/-}\right.$, $0.65 \pm 0.02, n=7 ; D R 6^{-1-}, 0.74 \pm 0.05$ spines $/ \mu \mathrm{m}, n=10$ animals; $D R 6^{+/+}$vs $D R 6^{+/-}, p \leq 0.01 ; D R 6^{ \pm}$vs $D R 6^{-1-}, p=$ 0.17 paired Student's $t$ test), reminiscent of the reported gene dose effect of APP on spine density of L5 pyramidal neurons (Bittner et al., 2009). Together, these data indicate that loss of DR6 phenocopies APP loss of function with respect to effects on dendritic spine density on cortical pyramidal neurons.

If DR6 functions with APP to regulate spine density then loss of both DR6 and APP function should mimic the loss of either DR6 or APP alone, i.e., the loss of function phenotypes should be nonadditive. To test this possibility, we crossed DR6 and APP knock-out animals and assessed spine density in 2 month old animals. Consistent with previous results, spine density was elevated in $\mathrm{L} 2 / 3$ pyramidal neurons in $A P P^{-/-} ; D R 6^{+/+}$animals (Fig. $2 E)\left(A P P^{+/+} ; D R 6^{-/-}\right.$animals were not included in this experiment since spine density in $D R 6^{-/-}$compared with $D R 6^{+/+}$had been assessed multiple times in the same background strain, C57BL/6). Importantly, spine density in $A P P^{-1-}$; $D R 6^{-1-}$ double knock-out animals did not differ from that in $A P P^{-1-} ; D R 6^{+/+}$animals (Fig. $2 E$ ), consistent with the model that DR6 and APP act within the same genetic pathway to regulate dendritic spine density in vivo.

To further understand the potential mechanism by which DR6 and APP regulate spine density, we assessed cell autonomy of APP and DR6 function with respect to spine density using shRNA targeted knockdown of each transcript in wild-type animals. In utero electroporation of an APP targeting construct, capable of $>90 \%$ APP knockdown in heterologous expression experiments (data not shown), into embryos resulted in a significant increase in spine density in the transfected $\mathrm{L} 2 / 3$ neurons of adult animals compared with control (Fig. $2 F$ ). Because transfection of the shRNA targeting construct was restricted to the analyzed L2/3 pyramidal neurons, due to the developmental timing of electroporation and confirmed by the detection of a coexpressed fluorescent protein, these data are consistent with the previously reported cell-autonomous activity of APP in the regulation of spine density in vitro (Wei et al., 2010). However, electroporation of a DR6 targeting construct, capable of a similar level of DR6 knockdown (Olsen et al., 2014), into embryos did not result in alterations of spine density within transfected neurons in adult animals (Fig. 2G). Consistent with this observation, electroporation of a DR6 expressing plasmid into L2/3 pyramidal neurons of $D R 6^{-1-}$ knock-out embryos did not rescue the elevated spine density phenotype observed in 2-month-old animals $\left(D R 6^{-1-} ; \mathrm{DR} 6(+), 0.81 \pm 0.05\right.$ spines $/ \mu \mathrm{m}, n=4$ animals; data collected in the same experiment reported in Fig. $2 C$ ). These results suggest that DR6 acts non-cell-autonomously with respect to regulating spine density, although we cannot exclude the possibility that DR6 also acts cell-autonomously but that shDR6 is less effective at eliminating its target in these neurons than is shAPP.
A

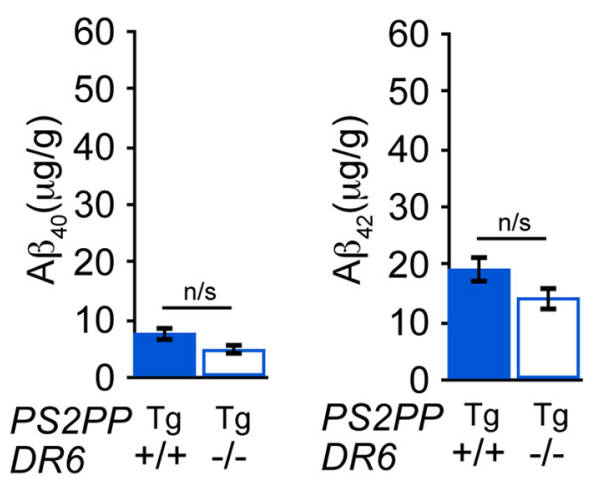

B
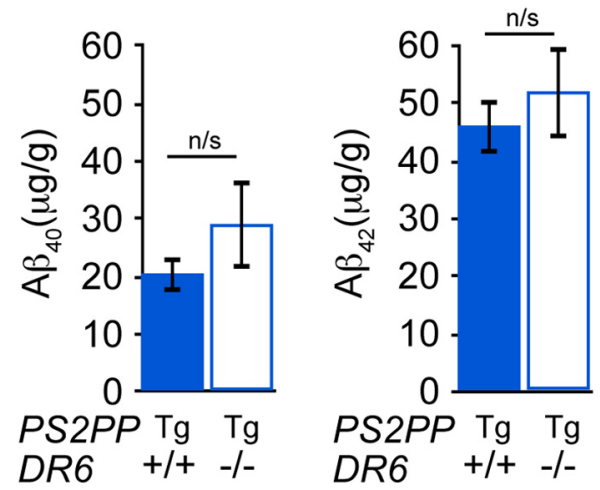

Figure 4. Loss of DR6 function does not alter $A \beta$ production in the PS2APP model of AD. $A$, Guanidine-extracted total $A \beta_{40}$ and $A \beta_{42}$ abundance in brain homogenates from 7-8 month PS2APP-Tg mice (PS2APP-Tg;DR6 ${ }^{+/+}, n=18 ;$ PS2APP-Tg;DR6 ${ }^{-1-}, n=16$ animals). $\boldsymbol{B}$, Total $A \beta_{40}$ and $A \beta_{42}$ abundance in 11-12 month PS2APP-Tg mice (PS2APP-Tg;DR6 ${ }^{+/+}, n=7$; PS2APP-Tg;DR6 ${ }^{-I-}, n=5$ animals).

Within the CNS, APP is proteolytically processed by the $\beta$-secretase protein, BACE-1, to give rise to soluble APP ectodomain, and if combined with $Y$-secretase cleavage, $A \beta$ peptides. To test whether BACE-1 activity contributes to the regulation of spine density, we assessed spines in L2/3 pyramidal neurons of $B A C E-1$ knock-out animals. In contrast to DR6 and APP knockout animals, spine density in $B A C E-1^{-1-}$ animals did not differ from $B A C E-1^{+/+}$control animals (Fig. $2 H$ ). Together these data are consistent with a model in which DR6 and APP act within the same genetic pathway to regulate spine density independent of BACE-1 activity. A similar lack of effect of genetic BACE-1 deletion has also been observed in the DR6- and APP-dependent pruning of retinal ganglion cell axons (Olsen et al., 2014).

\section{Loss of DR6 function does not rescue behavioral deficits in the PS2APP murine model of AD}

Our finding that DR6 and APP function in a BACE-1independent pathway to regulate dendritic spine density in vivo raises the question whether DR6 contributes to aspects of the pathophysiology of AD. To directly test whether DR6 contributes to APP-mediated AD-related cognitive deficits, we assessed whether DR6 loss of function alters behavioral phenotypes in the PS2APP model of AD at 7-8 months of age. PS2APP-Tg animals are homozygous for a transgene that expresses $\mathrm{AD}$-causing familial mutations in human presenilin-2 (N141I) and APP (K670N, M671L), and exhibit age-dependent behavioral deficits coincident with amyloid plaque deposition, neuroinflammation, and synaptic dysfunction compared with nontransgenic littermates (NTg; Richards et al., 2003; Ozmen et al., 2009). The Barnes Maze 
A

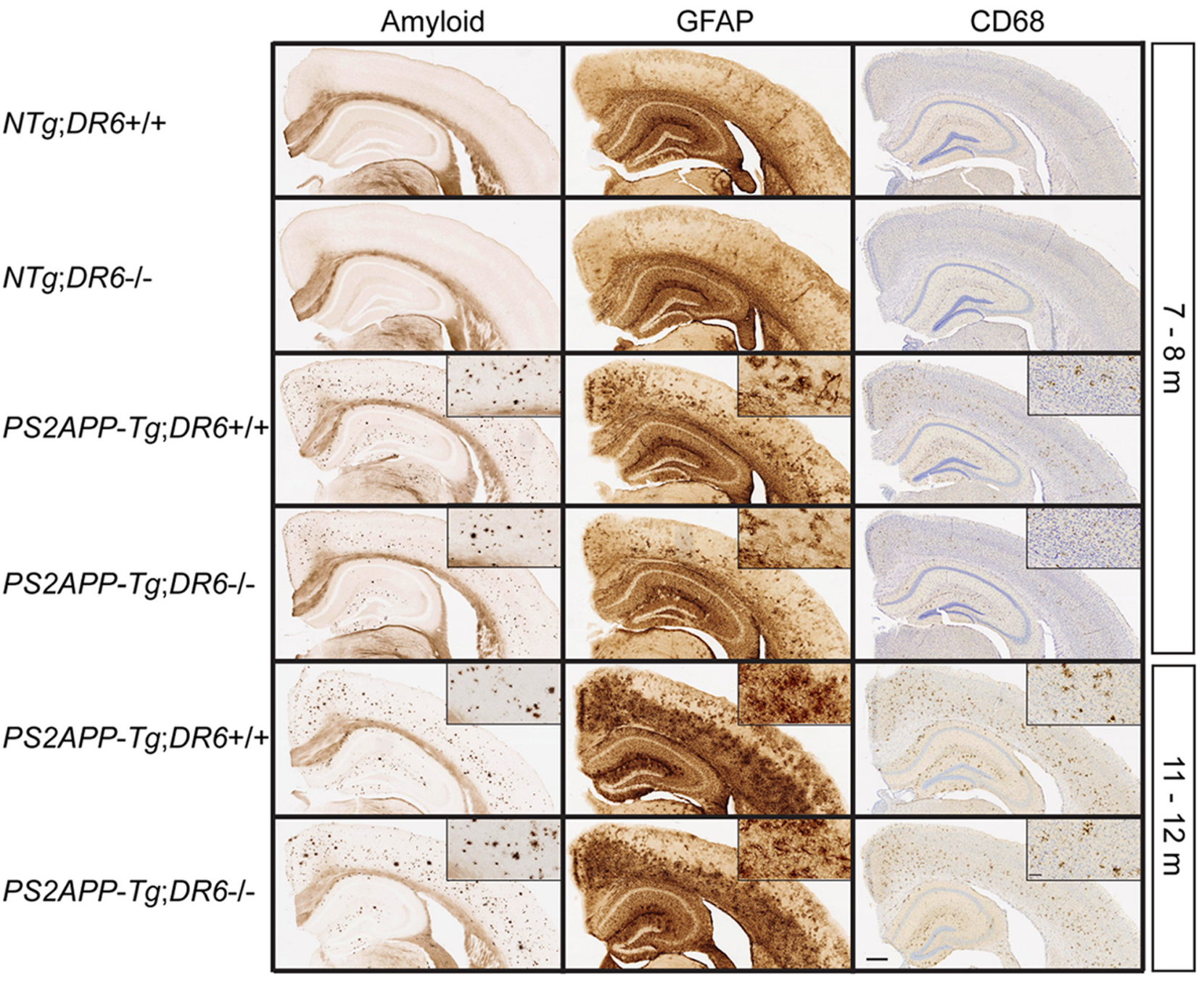

B
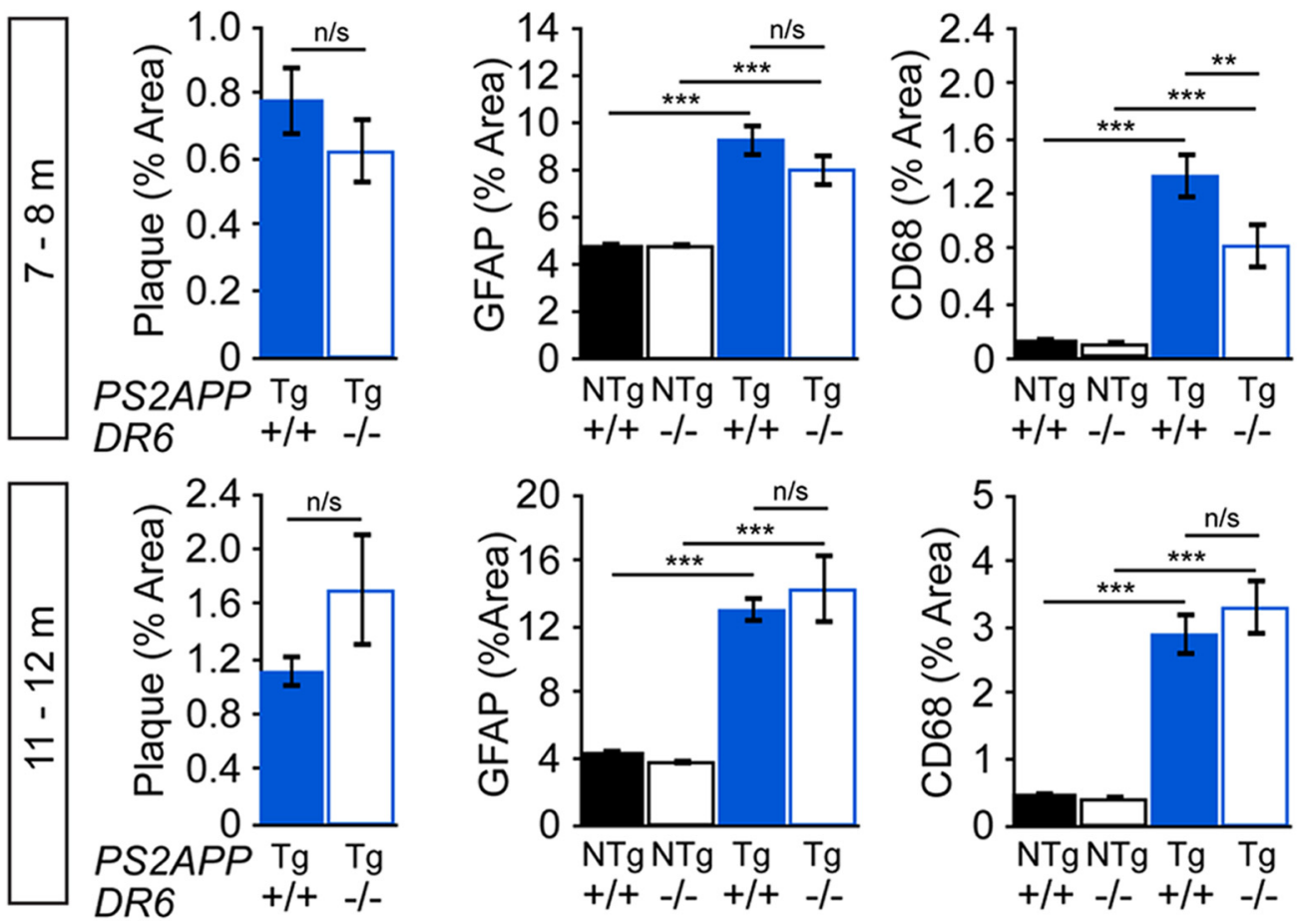

Figure 5. Loss of DR6 function does not ameliorate amyloid plaque or gliosis pathology in the PS2APP model of AD.A, Representative low-and high-magnification (inset) images of brain amyloid pathology and gliosis (GFAP and CD68) in 7-8 and 11-12 month mice. Plaque deposition was visualized by Campbell-Switzer staining, astrocytes by anti-GFAP IHC, and(Figure legend continues.) 
was used to assess the ability of animals to use spatial cues to find a hidden escape hole on a brightly lit platform. Learning can be tracked by quantifying the number of nose pokes into incorrect holes (errors) across successive training trials. $P S 2 A P P-T g$ animals exhibited a significant defect in learning this task, evidenced by increased number of errors per trial compared with $N T g$ animals (Fig. $3 A$ ). There was no difference between the PS2APP-Tg;DR6 ${ }^{+/+}$and PS2APP-Tg;DR6 ${ }^{-1-}$ animals. To assess memory retention, animals were tested $24 \mathrm{~h}$ after the final training session in a maze with no true escape hole. Compared with $N T g$ animals, PS2APP-Tg animals were less accurate in searching for the target hole during the probe trial (Fig. $3 B$ ). Loss of DR6 function, however, did not alter performance in either PS2APP-Tg or $N T g$ animals.

Similar results were found when spatial learning and memory were assessed using the Morris Water Maze. During the training phase, $P S 2 A P P-T g$ animals traveled a significantly greater distance (Fig. $3 C$ ), and took significantly longer (data not shown) to locate a hidden platform compared with NTg animals. Comparison of swim speeds during the hidden or visible platform training revealed no significant differences between groups (data not shown), and all animals learned to quickly locate a cued platform (Fig. 3C), suggesting that the deficits cannot be attributed to sensorimotor defects. Loss of DR6 function did not improve performance, as no differences were found between the PS2APP-Tg; $D R 6^{+/+}$and PS2APP-Tg;DR6 ${ }^{-1-}$ animals for either hidden or visible training. To assess spatial memory retention, animals were tested $72 \mathrm{~h}$ after the completion of hidden platform training (Fig. $3 D$ ). Compared with $N T g$ animals, PS2APP-Tg animals failed to search predominantly in the target zone versus all other corresponding zones (opposite, adjacent right, and adjacent left), and crossed over the target zone significantly fewer times (Fig. 3D), consistent with a defect in spatial memory. Loss of DR6 function did not alter performance in either the PS2APP-Tg or NTg animals.

Murine models of AD have also been reported to exhibit behavioral deficits in nonspatial associative learning tasks, such as active avoidance and contextual fear conditioning (Richards et al., 2003). During active avoidance training, animals learn to avoid a foot shock by shuttling to the opposite side of the test chamber within $5 \mathrm{~s}$ of the appearance of a warning cue. Similar to previous studies (Richards et al., 2003), PS2APP-Tg;DR6 ${ }^{+/+}$ mice displayed a significant impairment in avoidance learning on Day 1 of training (Fig. 3E), but performed similarly to NTg; $D R 6^{+/+}$mice by Day 2. Interestingly, loss of DR6 function alone resulted in alterations in this behavior as $N T g ; D R 6^{-1-}$ and $P S 2 A P P-T g ; D R 6^{-1-}$ mice exhibited a significant increase in avoidance responses compared with $N T g ; D R 6^{+/+}$and PS2APP$T g ; D R 6^{+/+}$animals. Because similar improvements were seen in

$\leftarrow$

(Figure legend continued.) microglia by anti-CD68 IHC. Scale bars: $A, 300 \mu \mathrm{m}$; inset, $60 \mu \mathrm{m}$. $B$, Quantification of staining for plaque, GFAP, and CD68 in 7-8 and 11-12 month animals. There were no significant differences in plaque load between the PS2APP-Tg;DR6 ${ }^{+/+}$and PS2APP-Tg;DR6 ${ }^{-1-}$ mice at either age. Analysis of GFAP and CD68 staining by ANOVA found a significant main effect of PS2APP genotype $(p<0.0001)$ in both ages. At 7-8 months, loss of DR6 function resulted in a significant reduction in CD68 staining (NTg; $\mathrm{DRG}^{+/+}, 0.14 \pm 0.02, n=20 ; \mathrm{NTg}^{\text {DRR6 }}{ }^{-1-}, 0.11 \pm 0.01, n=19 ;$ PS2APP-Tg; $D R 6^{+/+}, 1.34 \pm 0.18, n=18 ;$ PS2APP-Tg;DR6 ${ }^{-1-}, 0.83 \pm 0.11 \%$ Area, $n=16$ animals). A two-way ANOVA found a significant main effect of $D R 6$ genotype $(p<0.001)$ and a PS2APP DR6 interaction $(p<0.01)$. However, no difference was detected at 11-12 months (NTg;DR6 ${ }^{+/+}, 0.48 \pm 0.04, n=9 ; N T g ; D R 6^{-1-}, 0.41 \pm 0.02, n=9 ;$ PS2APP$\mathrm{Tg}_{\mathrm{D} D R 6^{+/+}}, 2.91 \pm 0.34, n=7 ;$ PS2APP-Tg;DR6 ${ }^{-1-}, 3.31 \pm 0.44 \%$ area, $n=5$ animals).
A
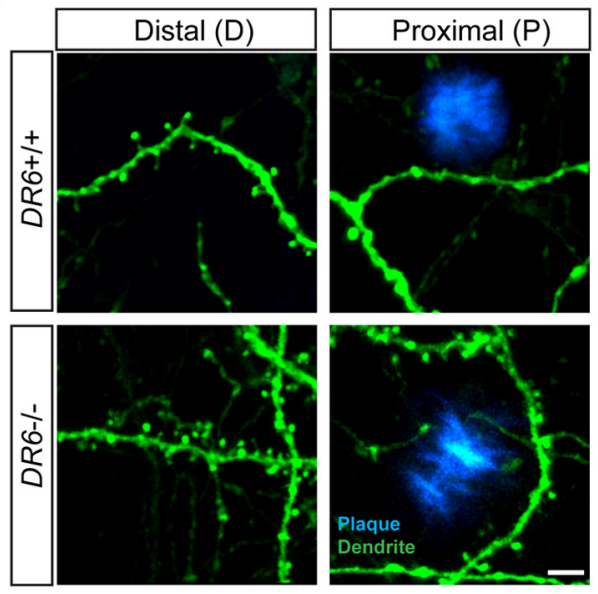

B

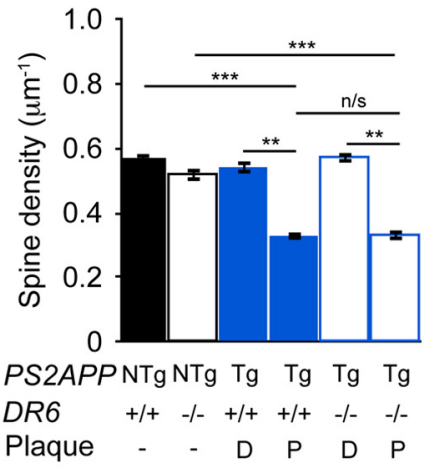

C

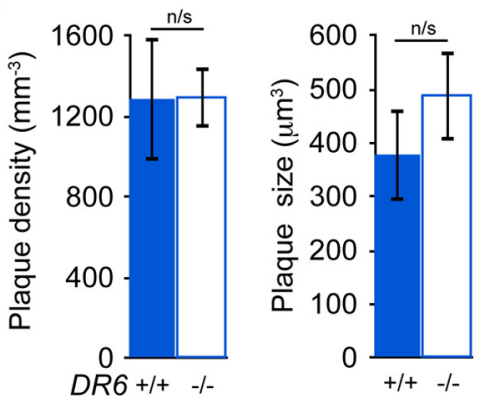

Figure 6. Loss ofDR6 function does not prevent spine loss associated with amyloid plaque in the PS2APP murine model of AD. $A$, Representative images of apical dendrite segments from $L 5$ pyramidal neurons either distal or proximal to amyloid plaques in 6 month PS2APP-Tg;DR6 ${ }^{+1+}$ and PS2APP-Tg;DR6 ${ }^{-1-}$ animals. Scale bar, $5 \mu \mathrm{m}$. $\boldsymbol{B}$, Quantification of spine density in relation to amyloid plaque proximity reveals a reduction of spine density on dendrites proximal $(P)$ to plaques compared with distal (D) in PS2APP-Tg;DR6 ${ }^{-1-}$ similar to PS2APP-Tg;DR6 ${ }^{+1+}$ animals (NTg;DR6 ${ }^{+1+}, 0.57 \pm 0.02, n=7 ;$ NTg;DR6 ${ }^{-1-}, 0.52 \pm 0.02, n=9 ;$ PS2APP-Tg; $D R 6^{+1+}$, distal $0.54 \pm 0.02$, proximal $0.33 \pm 0.01, n=16 ;$ PS2APP-Tg;DR6 ${ }^{-1-}$, distal $0.57 \pm 0.02$, proximal $0.33 \pm 0.02$ spines $/ \mu \mathrm{m}, n=15$ animals). C, Amyloid plaque density and size within the cortex was not altered with loss of DR6 function (PS2APP-Tg;DR6 ${ }^{+1+}$, density $1286 \pm 305$, size $378 \pm 86, n=16$ animals; PS2APP-Tg;DR6 ${ }^{-l-}$, density $1293 \pm 150$ plaques $/ \mathrm{mm}^{3}$, size $488 \pm 84 \mu \mathrm{m}^{3}, n=15$ animals).

$D R 6^{-1-}$ animals regardless of the presence or absence of the PS2APP transgene, we cannot conclude that loss of DR6 function rescues the PS2APP deficit. Rather the loss of DR6 seems to directly influence behavior on this task.

To determine whether the alterations in avoidance behavior in $D R 6^{-1-}$ animals are due to differences in activity levels, we measured spontaneous locomotor activity in an open-field paradigm over three separate 15 min sessions. DR6 ${ }^{-1-}$ animals exhibited a significant decrease in activity, traveling a significantly 
shorter distance (Fig. 3F); a phenotype which would be predicted to result in a decrease in active avoidance rather than the increase observed in $D R 6^{-1-}$ animals. $P S 2 A P P-T g$ genotype did not alter activity in this assay.

We further evaluated the potential role for DR6 in associative learning tasks by assessing whether DR6 knock-out alters contextual fear conditioning. During fear conditioning training, animals received two pairings of a $30 \mathrm{~s}$ tone that coterminated with a $2 \mathrm{~s}$ foot shock. Analysis of freezing behavior immediately after the second training foot shock revealed that $D R 6^{-1-}$ animals froze significantly more than $D R 6^{+/+}$animals, regardless of the PS2APP genotype (Fig. 3G). Twenty-four hours later, mice were placed back into the same chambers used during training to test their context memory. Again, the $D R 6^{-1-}$ animals froze significantly more than the $D R 6^{+/+}$animals (Fig. $3 H$ ). This altered behavior was limited to context memory, as cued memory testing in an altered context $4 \mathrm{~h}$ later revealed no significant difference in freezing behavior either in the altered context alone, or during the tone presentation.

Together our behavioral analysis of PS2APP-Tg animals indicates that the absence of DR6 does not ameliorate the behavioral deficits in the PS2APP model of AD; however, there are some behavioral changes that can be attributed to loss of DR6 function alone.

\section{Loss of DR6 function does not ameliorate amyloid plaque formation, gliosis, or synapse loss in the PS2APP murine model of AD}

We next examined the brains of 7- to 8-month-old animals following behavioral analysis and an additional 11- to 12-monthold cohort to determine whether DR6 deletion alters A $\beta$ pathology and gliosis in the PS2APP model. Analysis of guanidine-extracted total $\mathrm{A} \beta$ levels from forebrain samples did not reveal a difference between behaviorally tested PS2APP-Tg;DR6 ${ }^{+/+}$or PS2APP-Tg;DR6 ${ }^{-1-}$ animals at $7-8$ (Fig. $4 A$ ) or 11-12 months of age in an independent cohort (Fig. $4 \mathrm{~B})$. Consistent with our biochemical analysis, immunohistochemical staining for $\mathrm{A} \beta$ plaques did not reveal a difference in total amyloid plaque burden between DR6 genotypes (Fig. 5). To determine whether DR6 deletions alter plaque-associated gliosis, we stained neighboring sections for GFAP, an indicator of activated astrocytes, or CD68, an indicator of activated microglia. Consistent with previous studies, GFAP staining covered more brain area in samples from $P S 2 A P P-T g$ animals; however, it did not differ between PS2APP-Tg;DR6 ${ }^{+/+}$and PS2APP-Tg;DR6 ${ }^{-1-}$ animals (Fig. 5). Analysis of CD68+ staining also revealed a significant increase in staining in sections from PS2APP-Tg animals. Interestingly, CD68 + staining was significantly lower in sections from 7-8 month PS2APP-Tg;DR6 ${ }^{-1-}$ animals compared with $P S 2 A P P-T g ; D R 6^{+/+}$animals. However, this effect was not observed in 11- to 12-month-old animals. Together, these data suggest that loss of DR6 function does not grossly impact the pathogenic processing of APP or gliosis in the PS2APP model of

Figure 7. Loss of DR6 function does not alter spatial learning and memory deficits or pathology in the APP41 murine model of platform training $(p<0.01$, two-way repeated-measures ANOVA). $\boldsymbol{B}$, Percentage time signifies chance performance; $n=70$ APP41-NTg;DR6 ${ }^{+/+}, 56$ APP41-Tg;DR6 ${ }^{+/+}$, and 44 APP41-Tg;DR6 ${ }^{-1-}$ mice. C, Quanti-

A $1200 \rightarrow A P P 41-N T g: D R 6+/+$ B \begin{tabular}{ccccc}
2 & 3 & 4 & $V_{1}$ & $V_{2} V_{3} V_{4}$ \\
Session & \multicolumn{1}{c}{ Trial }
\end{tabular}

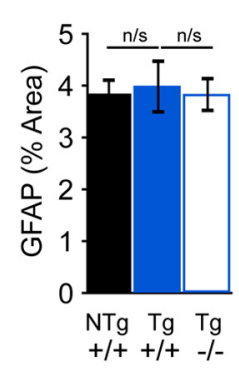

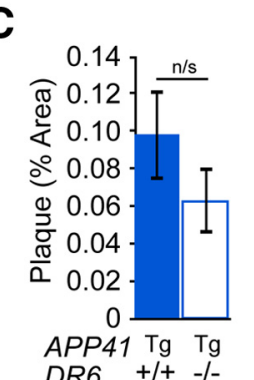

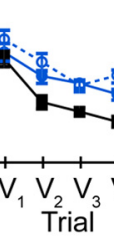

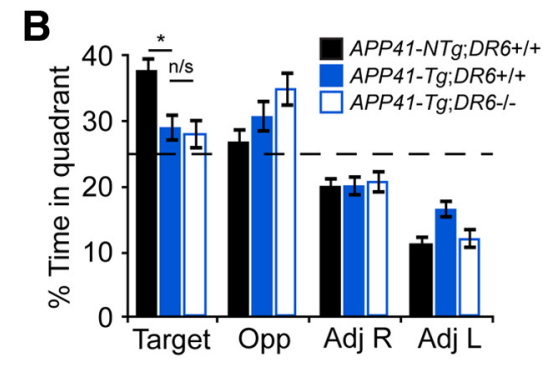

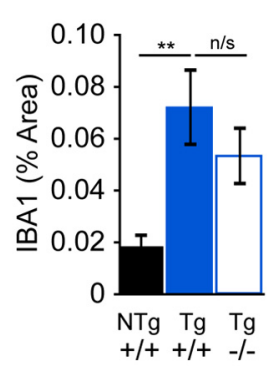

(1)
$-A P P 41-T g ; D R 6+/+$
$0-A P P 41-T g ; D R 6-/-$

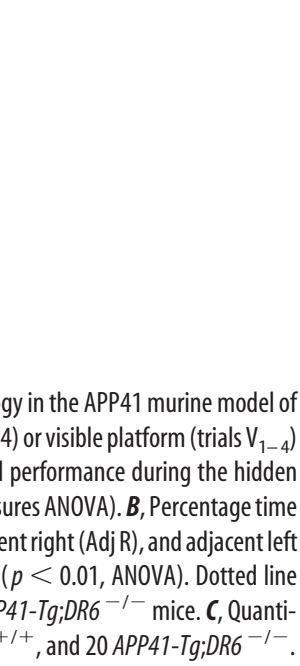

$\mathrm{AD}$, but also raises the possibility that DR6 plays a modest and transient modulatory role in microglia; an observation that needs to be confirmed with further analysis.

Another salient pathology associated with $\mathrm{AD}$ is a decrease in synapse density during disease progression (DeKosky and Scheff, 1990; Terry et al., 1991), with greater reduction of synapses around amyloid plaques (Koffie et al., 2009), suggesting that APP, or its proteolytic products, contributes to focal synapse loss. To test whether an APP-DR6 pathway contributes to amyloidassociated synapse loss, we crossed PS2APP-Tg;DR6 ${ }^{-1-}$ animals to the GFP-M transgenic line to visualize neuronal morphology in the context of AD-related pathology. GFP-M transgenic animals express GFP within a subset of L5 pyramidal neurons in the cortex (Feng et al., 2000), thus enabling the morphometric analysis of neurons. To assess synapse loss, we quantified dendritic spine density on apical dendrites of L5 pyramidal neurons within the somatosensory cortex in 6-month-old animals. Quantification of spine density on dendrites proximal or distal to abundant cortical amyloid plaques revealed a focal reduction in spine density adjacent to amyloid plaques (Fig. 6A), reminiscent of focal synapse loss observed in AD patient samples. Loss of DR6 function did not prevent this defect, as dendrites proximal to amyloid plaques in $P S 2 A P P-T g ; D R 6^{-1-}$ animals exhibited a reduction in spine density comparable with PS2APP-Tg;DR6 ${ }^{+/+}$animals (Fig. $6 B)$, suggesting that DR6 is not required for synapse loss associated with APP-driven amyloid plaque pathology.

\section{Loss of DR6 function does not rescue deficits in an alternate APP murine model of AD}

One concern in the evaluation of phenotypes in transgenic models of $\mathrm{AD}$ is that some of the phenotypes may be specific to the particular model and not generalizable to other models or representative of the fundamental biology underlying AD. Therefore, 
we also tested whether loss of DR6 function alters the behavioral and pathological phenotypes observed in an APP-only driven AD model, the hAPP ${ }_{\text {lon/swe }}$ line 41 (Rockenstein et al., 2001). Similar to $P S 2 A P P-T g$ animals, animals positive for the APP41 transgene, $A P P 41-T g$, express high levels of $A \beta_{1-40}$ and $A \beta_{1-42}$, begin to develop amyloid plaques at 3-4 months of age, and exhibit defects in spatial learning and memory compared with control littermates, APP41-NTg (Rockenstein et al., 2001; Faizi et al., 2012). Because this experiment was designed to test the effect of DR6 loss of function on deficits associated with the APP41 transgene, a APP41-NTg;DR6 ${ }^{-1-}$ cohort was not included in the study. In the Morris Water Maze, 6- to 7-month-old APP41-Tg animals traveled a significantly greater distance to locate the hidden or visible platform during training compared with APP41-NTg animals (Fig. 7A), although all animals eventually learned the task. Loss of DR6 function did not alter this response. Comparison of swim speeds during the hidden platform training found no significant differences between the groups (data not shown), suggesting the defect is cognitive. During a probe trial $24 \mathrm{~h}$ after the completion of hidden platform training, APP41- Tg animals failed to search predominantly in the target quadrant compared with all other corresponding quadrants (opposite, adjacent right, and adjacent left), and spent significantly less time searching in the target quadrant compared with APP41$N T g$ controls (Fig. $7 B$ ), consistent with a deficit in spatial memory. There was no difference between APP41-Tg;DR6 ${ }^{+/+}$ and APP41-Tg;DR6 ${ }^{-1-}$ animals.

Upon completion of behavioral experiments, brains were collected for histological analysis. Similar to our results from the PS2APP model, loss of DR6 function did not significantly alter amyloid plaque load or gliosis in APP41-Tg animals (Fig. 7C). Together, our biochemical, histological, and behavioral analysis of DR6 knock-outs in two distinct models of $\mathrm{AD}$ failed to find evidence that DR6 functions in their APP-related pathology.

\section{Discussion}

The identification of molecular pathways by which APP and its proteolytic fragments promote neurodegeneration is of great interest in the hopes of identifying potential targets for the treatment of $\mathrm{AD}$. In this study, we conducted genetic studies to evaluate DR6 function in the mature nervous system and in the context of APP function, both under normal and AD-related conditions. We found that although DR6 and APP function within the same genetic pathway to regulate the density of excitatory synapses onto pyramidal neurons in the adult, loss of DR6 function does not ameliorate the pathological phenotypes associated with two distinct murine models of AD.

Previous studies have implicated APP in the regulation of synapse density, both in vitro and in vivo (Priller et al., 2006; Bittner et al., 2009; Wei et al., 2010). Here we extend these findings in two important ways. First, through analysis of BACE-1 knock-out animals we provide evidence that APP-mediated physiological regulation of synapse density in vivo is BACE-1-independent, thus likely independent of $A \beta$ or additional BACE-1-cleaved APP products (s- $\beta$ APP or $\beta$-CTFs). Second, our genetic analysis of $A P P$ and DR6 single knock-out, and APP;DR6 double knockouts, supports a model in which APP regulates synapse density through a shared genetic pathway with DR6, because a similar phenotype was seen in the double mutant as in each of the single mutants. As the ectodomains of DR6 and APP have been shown to interact directly (Nikolaev et al., 2009; Olsen et al., 2014), the regulation of synapse density could be through a direct interaction. Further examination of APP and DR6, however, is required to determine whether an interaction is obligatory for function, and whether APP and DR6 represent a ligand-receptor pair or function via another modality, such as scaffolding molecules or coreceptors, to regulate synapse density.

Understanding how DR6 and APP regulate synapse density requires identifying the cellular context in which the pathway acts, and the timing of their action. In the context of regulating developmental axon degeneration, in vivo shRNA-knockdown of either DR6 or APP results in delayed developmental pruning of axons from transfected neurons, suggestive that both proteins can act cell-autonomously, likely within axons, to promote degeneration during development (Olsen et al., 2014). In analogous experiments, here in L2/3 pyramidal neurons of the mature CNS, shRNA-knockdown of APP within postsynaptic cells supported a cell-autonomous role for APP with respect to the regulation of spine density, but shRNA-knockdown of DR6 did not. One possibility is that DR6 functions in the presynaptic compartment and APP in the postsynaptic compartment to mediate their effects; we cannot, however, exclude that shDR6 was simply less effective than shAPP in knocking down its target and that both function in the postsynaptic compartment. With respect to timing of their action, the finding that DR6 regulates axon pruning during induced plasticity in the adult (Marik et al., 2013), raises the possibility that the effects on synapse density reflect ongoing roles for DR6 and APP in the adult. However, we also cannot exclude that the differences in synapse number reflect altered connectivity established during development, e.g., if more axons are retained after development in APP and DR6 knock-out mice, with increased synaptic density being a secondary consequence via altering the probability of presynaptic and postsynaptic cell contact. Interestingly, DR6 knock-out animals are reported to exhibit an increase in the density of presynaptic boutons but no change in bouton stability (Marik et al., 2013), consistent with the findings here of elevated dendritic spine density but no change in spine stability in DR6 knock-out animals. The lack of effect on bouton and spine stability might be interpreted to support the idea that increased synaptic density in adult $A P P$ and $D R 6$ knock-out mice is a secondary consequence of increased connectivity established in development, although further studies, including removal of APP and/or DR6 specifically in the adult, will be required to definitively rule in or rule out ongoing roles for these proteins in regulating synaptic density in the adult.

In line with altered spine density in DR6 ${ }^{-1-}$ animals, several behavioral abnormalities were observed in mice lacking DR6. Specifically, they showed reduced spontaneous locomotion in an open field, increased freezing response to a foot shock, and faster learning to avoid a shock in an active avoidance task. Given the lack of DR6 effect in more demanding cognitive tasks, such as the Barnes Maze and Morris Water Maze, it is likely that these changes reflect alterations in reactivity to novel and/or aversive stimuli. Although we did not test $A P P^{-/-}$mice in the battery of behavioral tests described here, several APP-deficient mouse lines have been characterized previously (Müller et al., 1994; Dawson et al., 1999; Ring et al., 2007; Senechal et al., 2008). Interestingly, like $D R 6^{-/-}$mice, $A P P^{-1-}$ animals are reported to show reduced locomotion in an open field. This is also potentially consistent with the idea that DR6 and APP act in the same pathway to alter neuronal morphology and function, though because there are many ways that locomotor activity can be altered, alternate pathways may also be involved. Interestingly, $A P P^{-1-}$ mice were also reported to have altered active avoidance behaviors (Müller et al., 1994; Dawson et al., 1999; Senechal et al., 2008). Although most of these studies found that older $A P P^{-/-}$animals 
were slower to acquire avoidance behavior, Dawson et al. (1999) noted that young (4-month-old) $A P P^{-/-}$animals tended to acquire avoidance faster than the $A P P^{+/+}$controls-similar to the results found here with $D R 6^{-1-}$ mice. However, in contrast to these two similarities in behavioral alterations in $D R 6^{-1-}$ mice and $A P P^{-1-}$ mice, there is a notable divergence between these mice in spatial learning and memory. Morris Water Maze deficits are widely reported in $A P P^{-1-}$ mice (Müller et al., 1994; Dawson et al., 1999; Ring et al., 2007), although we see no evidence of spatial learning impairments in $D R 6^{-l-}$ mice. This suggests that removal of APP can affect neural function and behavior through some pathways that are dependent on DR6 function but others that are independent.

Although studies of DR6 and APP knock-out animals suggest that APP can function in both DR6-dependent and -independent pathways in vivo, it is important to understand if the relationship between the two proteins is similar or different in the disease context. Our genetic analysis of DR6 in murine models of AD indicates that DR6 is not required for most of the APP-driven $\mathrm{AD}$-related pathology that is apparent in two distinct APP overexpression models. No difference was observed in the appearance of amyloid plaques or in gliosis, though a role for DR6 in these processes was not necessarily expected; there was, however, an apparent transient reduction in the degree of microglial activation, although further studies will be required to confirm this effect and determine its basis. However, given the interaction of DR6 and APP and the report that DR6 functions to mediate toxic actions of $\mathrm{A} \beta$ peptides in vitro (Hu et al., 2013), one might have expected DR6 removal to mitigate synaptic loss and/or cognitive behavioral deficits, especially because those defects in mouse models appear to be dependent on $\mathrm{A} \beta$ because they can be improved by administration of antibodies to $\mathrm{A} \beta$ (Brody and Holtzman, 2008). However, we did not observe any reversal of those deficits upon genetic deletion of DR6. Our results, therefore, argue against a central role for DR6 in establishing APP and/or A $\beta$ driven pathology in these mice. Whether it contributes to the axon degeneration observed in Alzheimer's disease remains to be determined.

\section{References}

Athan ES, Williamson J, Ciappa A, Santana V, Romas SN, Lee JH, Rondon H, Lantigua RA, Medrano M, Torres M, Arawaka S, Rogaeva E, Song YQ, Sato C, Kawarai T, Fafel KC, Boss MA, Seltzer WK, Stern Y, St GeorgeHyslop P, et al. (2001) A founder mutation in presenilin 1 causing earlyonset Alzheimer disease in unrelated Caribbean Hispanic families. JAMA 286:2257-2263. CrossRef Medline

Atwal JK, Chen Y, Chiu C, Mortensen DL, Meilandt WJ, Liu Y, Heise CE, Hoyte K, Luk W, Lu Y, Peng K, Wu P, Rouge L, Zhang Y, Lazarus RA, Scearce-Levie K, Wang W, Wu Y, Tessier-Lavigne M, Watts RJ (2011) A therapeutic antibody targeting BACE1 inhibits amyloid- $\beta$ production in vivo. Sci Transl Med 3:84ra43. CrossRef Medline

Bevis BJ, Glick BS (2002) Rapidly maturing variants of the Discosoma red fluorescent protein (DsRed). Nat Biotechnol 20:83-87. CrossRef Medline

Bittner T, Fuhrmann M, Burgold S, Jung CK, Volbracht C, Steiner H, Mitteregger G, Kretzschmar HA, Haass C, Herms J (2009) Gamma-secretase inhibition reduces spine density in vivo via an amyloid precursor protein-dependent pathway. J Neurosci 29:10405-10409. CrossRef Medline

Brickell KL, Leverenz JB, Steinbart EJ, Rumbaugh M, Schellenberg GD, Nochlin D, Lampe TH, Holm IE, Van Deerlin V, Yuan W, Bird TD (2007) Clinicopathological concordance and discordance in three monozygotic twin pairs with familial Alzheimer's disease. J Neurol Neurosurg Psychiatr 78:1050-1055. CrossRef Medline

Brody DL, Holtzman DM (2008) Active and passive immunotherapy for neurodegenerative disorders. Annu Rev Neurosci 31:175-193. CrossRef Medline

Cruchaga C, Haller G, Chakraverty S, Mayo K, Vallania FL, Mitra RD, Faber
K, Williamson J, Bird T, Diaz-Arrastia R, Foroud TM, Boeve BF, GraffRadford NR, St Jean P, Lawson M, Ehm MG, Mayeux R, Goate AM, NIA-LOAD/NCRAD Family Study Consortium (2012) Rare variants in APP, PSEN1 and PSEN2 increase risk for AD in late-onset Alzheimer's disease families. PLoS ONE 7:e31039. CrossRef Medline

Cruts M, van Duijn CM, Backhovens H, Van den Broeck M, Wehnert A, Serneels S, Sherrington R, Hutton M, Hardy J, St George-Hyslop PH, Hofman A, Van Broeckhoven C (1998) Estimation of the genetic contribution of presenilin-1 and -2 mutations in a population-based study of presenile Alzheimer disease. Hum Mol Genet 7:43-51. CrossRef Medline

Dawson GR, Seabrook GR, Zheng H, Smith DW, Graham S, O'Dowd G, Bowery BJ, BoyceS, Trumbauer ME, Chen HY, Van der PloegLH, SirinathsinghjiDJ (1999) Age-related cognitive deficits, impaired long-term potentiation and reduction in synaptic marker density in mice lacking the beta-amyloid precursor protein. Neuroscience 90:1-13. CrossRef Medline

DeKosky ST, Scheff SW (1990) Synapse loss in frontal cortex biopsies in Alzheimer's disease: correlation with cognitive severity. Ann Neurol 27: 457-464. CrossRef Medline

Faizi M, Bader PL, Saw N, Nguyen TV, Beraki S, Wyss-Coray T, Longo FM, Shamloo M (2012) Thyl-hAPP(Lond/Swe+) mouse model of Alzheimer's disease displays broad behavioral deficits in sensorimotor, cognitive and social function. Brain Behav 2:142-154. CrossRef Medline

Feng G, Mellor RH, Bernstein M, Keller-Peck C, Nguyen QT, Wallace M, Nerbonne JM, Lichtman JW, Sanes JR (2000) Imaging neuronal subsets in transgenic mice expressing multiple spectral variants of GFP. Neuron 28:41-51. CrossRef Medline

Foldi CJ, Eyles DW, McGrath JJ, Burne TH (2011) The effects of breeding protocol in C57BL/6J mice on adult offspring behaviour. PLoS ONE 6:e18152. CrossRef Medline

Gray NW, Weimer RM, Bureau I, Svoboda K (2006) Rapid redistribution of synaptic PSD-95 in the neocortex in vivo. PLoS Biol 4:e370. CrossRef Medline

Hardy JC, Crook P (2010) APP mutations table:1-2. http://www.alzforum. org/mutations. Accessed October 21, 2013.

Holtmaat A, Bonhoeffer T, Chow DK, Chuckowree J, De Paola V, Hofer SB, Hübener M, Keck T, Knott G, Lee WC, Mostany R, Mrsic-Flogel TD, Nedivi E, Portera-Cailliau C, Svoboda K, Trachtenberg JT, Wilbrecht L (2009) Long-term, high-resolution imaging in the mouse neocortex through a chronic cranial window. Nat Protoc 4:1128-1144. CrossRef Medline

Holtzman DM, Morris JC, Goate AM (2011) Alzheimer's disease: the challenge of the second century. Sci Transl Med 3:77sr1. CrossRef Medline

Hu Y, Lee X, Shao Z, Apicco D, Huang G, Gong BJ, Pepinsky RB, Mi S (2013) complex is responsible for. Cell Death and Disease 4:e579-8. CrossRef Medline

Jonsson T, Atwal JK, Steinberg S, Snaedal J, Jonsson PV, Bjornsson S, Stefansson H, Sulem P, Gudbjartsson D, Maloney J, Hoyte K, Gustafson A, Liu Y, Lu Y, Bhangale T, Graham RR, Huttenlocher J, Bjornsdottir G, Andreassen OA, Jönsson EG, Palotie A (2012) A mutation in APP protects against Alzheimer's disease and age-related cognitive decline. Nature 488: 96-99. CrossRef Medline

Kasof GM, Lu JJ, Liu D, Speer B, Mongan KN, Gomes BC, Lorenzi MV (2001) Tumor necrosis factor-alpha induces the expression of DR6, a member of the TNF receptor family, through activation of NF-kappaB. Oncogene 20:7965-7975. CrossRef Medline

Klunk WE, Bacskai BJ, Mathis CA, Kajdasz ST, McLellan ME, Frosch MP, Debnath ML, Holt DP, Wang Y, Hyman BT (2002) Imaging AB plaques in living transgenic mice with multiphoton microscopy and methoxyX04, a systemically administered Congo red derivative. J Neuropathol Exp Neurol 61:797-805. Medline

Koffie RM, Meyer-Luehmann M, Hashimoto T, Adams KW, Mielke ML, Garcia-Alloza M, Micheva KD, Smith SJ, Kim ML, Lee VM, Hyman BT, Spires-Jones TL (2009) Oligomeric amyloid beta associates with postsynaptic densities and correlates with excitatory synapse loss near senile plaques. Proc Natl Acad Sci U S A 106:4012-4017. CrossRef Medline

Le Pichon CE, Dominguez SL, Solanoy H, Ngu H, Lewin-Koh N, Chen M, Eastham-Anderson J, Watts R, Scearce-Levie K (2013) EGFR inhibitor erlotinib delays disease progression but does not extend survival in the SOD1 mouse model of ALS. PLoS ONE 8:e62342. CrossRef Medline

Luo L, O'Leary DD (2005) Axon retraction and degeneration in development and disease. Annu Rev Neurosci 28:127-156. CrossRef Medline

Marik SA, Olsen O, Tessier-Lavigne M, Gilbert CD (2013) Death receptor 6 
regulates adult experience-dependent cortical plasticity. J Neurosci 33: 14998-15003. CrossRef Medline

Müller U, Cristina N, Li ZW, Wolfer DP, Lipp HP, Rülicke T, Brandner S, Aguzzi A, Weissmann C (1994) Behavioral and anatomical deficits in mice homozygous for a modified beta-amyloid precursor protein gene. Cell 79:755-765. CrossRef Medline

Nikolaev A, McLaughlin T, O'Leary DD, Tessier-Lavigne M (2009) APP binds DR6 to trigger axon pruning and neuron death via distinct caspases. Nature 457:981-989. CrossRef Medline

Olsen O, Kallop DY, McLaughlin T, Huntwork-Rodriguez S, Wu Z, Duggan C, Simon D, Lu Y, Easley-Neal C, Takeda K, Hass PE, Jaworski A, O'Leary DDM, Weimer RM, Tessier-Lavigne M (2014) Genetic analysis reveals that Amyloid Precursor Protein and Death Receptor 6 function to control axonal pruning independent of beta-secretase. J Neurosci 34:6438-6447.

Ozmen L, Albientz A, Czech C, Jacobsen H (2009) Expression of transgenic APP mRNA is the key determinant for beta-amyloid deposition in PS2APP transgenic mice. Neurodegener Dis 6:29-36. CrossRef Medline

Pan G, Bauer JH, Haridas V, Wang S, Liu D, Yu G, Vincenz C, Aggarwal BB, Ni J, Dixit VM (1998) Identification and functional characterization of DR6, a novel death domain-containing TNF receptor. FEBS Lett 431:351356. CrossRef Medline

Priller C, Bauer T, Mitteregger G, Krebs B, Kretzschmar HA, Herms J (2006) Synapse formation and function is modulated by the amyloid precursor protein. J Neurosci 26:7212-7221. CrossRef Medline

Richards JG, Higgins GA, Ouagazzal AM, Ozmen L, Kew JN, Bohrmann B, Malherbe P, Brockhaus M, Loetscher H, Czech C, Huber G, Bluethmann H, Jacobsen H, Kemp JA (2003) PS2APP transgenic mice, coexpressing hPS2mut and hAPPswe, show age-related cognitive deficits associated with discrete brain amyloid deposition and inflammation. J Neurosci 23:8989-9003. Medline

Ring S, Weyer SW, Kilian SB, Waldron E, Pietrzik CU, Filippov MA, Herms J, Buchholz C, Eckman CB, Korte M, Wolfer DP, Müller UC (2007) The secreted betaamyloid precursor protein ectodomain APPs alpha is sufficient to rescue the anatomical, behavioral, and electrophysiological abnormalities of APP-deficient mice. J Neurosci 27:7817-7826. CrossRef Medline

Rockenstein E, Mallory M, Mante M, Sisk A, Masliaha E (2001) Early formation of mature amyloid-beta protein deposits in a mutant APP transgenic model depends on levels of Abeta(1-42). J Neurosci Res 66:573-582. CrossRef Medline

Rogaeva EA, Fafel KC, Song YQ, Medeiros H, Sato C, Liang Y, Richard E, Rogaev EI, Frommelt P, Sadovnick AD, Meschino W, Rockwood K, Boss
MA, Mayeux R, St George-Hyslop P (2001) Screening for PS1 mutations in a referral-based series of $\mathrm{AD}$ cases: 21 novel mutations. Neurology 57:621-625. CrossRef Medline

Saito T, Nakatsuji N (2001) Efficient gene transfer into the embryonic mouse brain using in vivo electroporation. Dev Biol 240:237-246. CrossRef Medline

Senechal Y, Kelly PH, Dev KK (2008) Amyloid precursor protein knockout mice show age-dependent deficits in passive avoidance learning. Behav Brain Res 186:126-132. CrossRef Medline

Shan ZX, Lin QX, Yang M, Deng CY, Kuang SJ, Zhou ZL, Xiao DZ, Liu XY, Lin SG, Yu XY (2009) A quick and efficient approach for gene silencing by using triple putative microRNA-based short hairpin RNAs. Mol Cell Biochem 323:81-89. CrossRef Medline

Simon DJ, Weimer RM, McLaughlin T, Kallop D, Stanger K, Yang J, O'Leary DD, Hannoush RN, Tessier-Lavigne M (2012) A caspase cascade regulating developmental axon degeneration. J Neurosci 32:17540-17553. CrossRef Medline

Tam SJ, Richmond DL, Kaminker JS, Modrusan Z, Martin-McNulty B, Cao TC, Weimer RM, Carano RA, van Bruggen N, Watts RJ (2012) Death receptors DR6 and TROY regulate brain vascular development. Dev Cell 22:403-417. CrossRef Medline

Terry RD, Masliah E, Salmon DP, Butters N, DeTeresa R, Hill R, Hansen LA, Katzman R (1991) Physical basis of cognitive alterations in Alzheimer's disease: synapse loss is the major correlate of cognitive impairment. Ann Neurol 30:572-580. CrossRef Medline

Wang A, Das P, Switzer RC 3rd, Golde TE, Jankowsky JL (2011) Robust amyloid clearance in a mouse model of Alzheimer's disease provides novel insights into the mechanism of amyloid-beta immunotherapy. J Neurosci 31:4124-4136. CrossRef Medline

Wei W, Nguyen LN, Kessels HW, Hagiwara H, Sisodia S, Malinow R (2010) Amyloid beta from axons and dendrites reduces local spine number and plasticity. Nat Neurosci 13:190-196. CrossRef Medline

Zhang YW, Thompson R, Zhang H, Xu H (2011) APP processing in Alzheimer's disease. Mol Brain 4:3. CrossRef Medline

Zhao H, Yan M, Wang H, Erickson S, Grewal IS, Dixit VM (2001) Impaired c-Jun amino terminal kinase activity and $\mathrm{T}$ cell differentiation in death receptor 6-deficient mice. J Exp Med 194:1441-1448. CrossRef Medline

Ziskin JL, Dunlap D, Yaylaoglu M, Fodor IK, Forrest WF, Patel R, Ge N, Hutchins GG, Pine JK, Quirke P, Koeppen H, Jubb AM (2013) In situ validation of an intestinal stem cell signature in colorectal cancer. Gut 62:1012-1023. CrossRef Medline 